\title{
Property, politics and the neo-liberal revolution in urban Scotland
}

\author{
Robert Rogerson and Mark Boyle \\ Department of Geography, University of Strathclyde, 50 Richmond Street, Glasgow G1 1XN, UK
}

\begin{abstract}
This paper is written in the context of current debates about the extent to which business coalitions are shaping the political agendas of the contemporary city. With a growing critique of the use of North American frameworks as a basis for the interpretation of business politics in the British city, we make a contribution towards the development of a more theoretically informed account of capital's involvement in local politics in Britain. Our research design takes analysis beyond the confines of what we term a 'state-centred perspective' insofar as we focus on the political behaviour of one key fraction of capital, property, in a range of urban areas in one political system, Scotland. Through the first survey to be conducted in Scotland of the political activities of property agents, the paper draws out conclusions about the extent to which new forms of neo-liberal urban governance are serving to construct an environment within which contemporary property politics are being played out. Our results point to a politically engaged fraction of capital but one which is largely oblivious to the changes in governance taking place around them. In an effort to further understanding property politics, we conclude that more attention needs to be given to capital and its trajectories. In calling for an epistemological shift towards a capital-centred perspective, we conclude that an understanding of property politics might profitably draw upon both a rehabilitated version of neo-Marxist frameworks and more recent institutional perspectives. (C) 2000 Elsevier Science Ltd All rights reserved.
\end{abstract}

E-mail address: r.j.rogerson@strath.ac.uk (R. Rogerson), mark.boyle@strath.ac.uk (M. Boyle). 


\section{CHAPTER 1}

\section{Business politics in the city}

According to Offe (1985), the business community in capitalist societies is not subjected to the same imperative to organise itself as a political force as other sections of the community, particularly say, labour. In his reading, this is due to the intrinsically powerful position which capital possesses in such societies, giving it unique access to the state. With globalisation, this power has clearly increased. The ever present threat, that capital operates with a heightened degree of mobility and may at a moment chose to withdraw from certain locations, is sufficient to ensure that state agendas privilege its interest without the need for any explicit political lobbying. It is clear, nevertheless, that at various moments in time and various locations, the business community does feel the need to organise itself into particular political forms to articulate its views to the state. The circumstances under which these moments arise, the institutional architecture through which the business community articulates its concerns, and the actual practices of lobbying remain, however, poorly researched. It is against this wider backdrop that this paper is situated.

Whilst the political activities of capital might occur across a range of scales, we focus here on only one scale - that of the local state. Further, our interest is confined to those local states most responsible for managing urban environments. By 'business politics' we mean the negotiated and contested interfaces between elements of the business community and the key institutions of urban governance. In this respect, our study encompasses both policy and practice - the issues around which politicking occurs and the actual practice of how such politicking takes place. Whilst considerable attention has been given to the new forms of urban governance which have emerged over the past two decades - and especially the development of coalitions and partnerships between the state and the private sector-much less attention has been paid to the 'business politics' which surround these developments. By focusing on a case study of one fraction of capital, property, in a range of urban locations in one setting, Scotland, we attempt to rectify this oversight and to add to the limited literature which does exists on the formal political activities of capital in the city.

In this opening chapter, we begin with a review of recent research on business politics in the North American city and consider current debates challenging the extent to which the key concepts in this literature are transferable to the British context. Studies of North American cities offer by far the most developed accounts of business politics at the urban level and, therefore, have been all too often taken as an entry point to the British scene. In the second section of the chapter, we turn attention to recent work, which suggests that the restructuring of the local state in United Kingdom is serving to construct a context within which new interfaces between the state and capital are developing. Therein business politics in the city has been located within an arena of state restructuring. How capital is responding to these new interfaces remains unclear however. This omission is, we contend, a most fundamental obstacle to understanding the nature of business political activity. Whilst using this state-centred thesis as a context, it is towards a more substantial understanding of the role of capital that the paper is devoted. To this end, the third section of the chapter will set out the main research questions that interest us. Our focus on one 
sector, property, and its activities in a range of different cities within Scotland, marks this paper out from previous work. In this and the final section of the chapter, consequently, we will explain why we have adopted this particular approach. As a prelude to the main study, we will finish with a review of the general sets of relations between the state and property that one might expect to exist at a theoretical level.

\subsection{Reflecting on differences between North American and British experiences of business coalitions}

Arguably, the most developed accounts of business politics in the city derive from studies conducted in North America. Here, despite being almost twenty years old, the concept of growth machines would seem to continue to exert enormous influence (Logan and Molotch, 1987; Jonas and Wilson, 1999). Growth machines represent amalgams of branches of the local state and fractions of local capital whom together operate to define and implement development objectives for the city. With the transformation within the local state from managerialist to entrepreneurial structures and strategies, the interests of capital tend to be privileged in these alliances. Indeed, what makes growth machines so unique is the central role the business community plays in actually forcing local politics along certain lines (Harvey, 1989). Moreover, the spontaneous formation of the business community into an organised political movement seems to be the primary driving force behind the North American local political scene (Wood, 1993). Central to the study of the politics of the business community in the North American city, therefore, is the analysis of the evolving interfaces between the local state and those fractions of capital involved in the local growth machine.

If the business community in North America has developed highly organised political forms at the urban level, the question remains as to why. Cox and his co-workers (Cox and Mair, 1988; Jonas, 1991, 1996; Cox, 1995; Wood, 1996) have argued that not only is the spatiality of the North American state a factor (where more power is vested at the local level) but so too is the spatiality of capital. The high degree of local dependence of capital—experienced by say banks, utility companies, newspaper companies and property developers - necessitates their active involvement in politics; heightened at a time when globalisation, greater capital mobility, and the rise of inter-urban competition places their interests under strain. For these authors, the extent to which capital is wedded to any locality is significant, and it is precisely those businesses which have a high level of local capital investment, local non-substitutable exchange relations, reliance on the local labour market, strong local knowledge and high overall locational concentration in an area that are most likely to form spontaneously into coalitions. When the context of these economic relations are threatened, these key fractions of capital may be motivated, spontaneously, to try collectively to harness the power of the local state (and other capital) to defend their interests. As Cox and Mair (1988: 310) express it, "locally dependent firms engage in collective strategies via business coalitions in order to realize their common interests in a particular area, interests that are antagonistic to those of locally dependent firms in other places".

Across the last decade there has grown an appreciation that the nature of business politics in British cities is radically different from that which prevails in North America. 
A number of studies which have attempted to compare the shape and form of urban regimes in both settings have noted a number of key differences (Stone, 1989; Ward, 1997). At a much more advanced level, a number of more critical studies have sought to delineate the problematic nature of applying concepts (such as 'growth machines', 'local dependence', and 'urban entrepreneurialism') with a US genealogy to UK cities (Lloyd and Newlands, 1988; Harding, 1991, 1994; Axford and Pinch, 1994; Ward, 1996, 1997; Wood, 1996; Rogerson and Boyle, 1998). The difficulty of exporting concepts beyond North America has only served to draw attention to the fact that they represent 'grounded constructions' (Ward, 1996). The consequence of this growing wariness of universalising North American theoretical frameworks has been the creation of something of a theoretical void in British studies. British geographers, it would seem, are currently floundering around in an effort to create theory which will allow an understanding of the specificities of the British case.

In this search, research has been taken in two principal directions. First, in contrast to the North American experience, research in the British context has pointed to the apparent lack of spontaneity in the formation of business coalitions. In seeking to understand the limited capacity of capital to self-organise in British cities, research has focused on the different characteristics of the business community in the two national settings. In particular, recent studies have begun to employ the concept of local dependence to assess the extent to which there are differences in the nature, structure and spatiality of capital in Britain (Harding, 1991; Ward, 1997; Rogerson and Boyle, 1998). Through specific illustrations, it has been concluded that the centralisation of capital in Britain makes it less inclined to be involved in local coalitions (Axford and Pinch, 1994; Wood, 1996). Importantly, this research marks out new and promising ground for future studies, in so far as it points to the need for greater insight into the institutional landscape of British capital. Clearly, there is more at stake here than arguments about local dependency, and a whole range of work needs to be undertaken regarding the different characteristics of capital. This will be an issue which we will return to at the end of this paper.

Up to now, however, in Britain most energy has been expended on research which looks at differences in the structure and strategies of the state. Here too, a wide range of studies has pointed to differences between North America and Britain. The centralisation of the British state in comparison to the more devolved, local structures of the state which prevail in North America, is normally taken to be the main point of departure. Further, the way in which the central state has sought to transform local government in Britain over the past two decades has been cited as being of critical importance, for these changes have served to catapult the local state into new relationships with the business community. It is in the shadow of these new relationships, it is argued, that a new breed of business politics can be detected in the United Kingdom. Whilst the study of business politics in North America is currently being understood in terms of the role of aggressive business coalitions in shaping the trajectory of political practice, British literature is pointing to the need to locate the study of business politics in the city within both the framework of a centrally directed restructuring of the British local state, and the new interfaces with capital these changes are bringing about. It is towards this argument that attention now turns. 


\subsection{The rise of the post-Fordist local state and the morphology of business politics in} British cities

Drawing upon various strands of regulation theory, there now exists a well developed literature on the changing structures and practices marking the governance of urban areas (and indeed rural areas) in the United Kingdom in the past two decades. In trying to contextualise these changes against the background of wider restructuring in capitalist production and consumption processes, and the changing institutional forms of the state which regulate particular regimes of accumulation, regulationinspired accounts have the virtue of going beyond mere description. The attraction of regulation theory, therefore, lies in its ability to relate recent trends in the British local state to changes in the wider economy and larger issues related to central government's effort to pursue a new mode of regulation. Whilst the purpose of this paper is certainly not to understand the contribution made by the local state in Scotland to the social and technical regulation of the Scottish economy in the late 1990s, it is worthwhile considering briefly some of the main theses to derive from this literature as they serve well to render contemporary local state trajectories in Scotland more comprehensible.

Arguably, the most useful overview of the changing contribution made by the local state to the wider apparatus regulating capitalist development in the United Kingdom is that provided by Goodwin and Painter (1996). Defining the terms 'local governance', 'regulation', and 'crises' with great care, Goodwin and Painter argue that a flaw in many earlier accounts of regulation theory was to assume that episodic periods, where state regulation of economic development 'worked', were the norm. Crises periods, where predominant modes of regulation and capitalist development are out of synchronisation, it was assumed would always be resolved and new regulatory structures would stabilise emerging regimes of accumulation at least for a time. In fact, there is no reason to expect periods of harmony to dominate. It would seem more likely, indeed, that crises and not stability ought to be the norm. Even if technocrats in any society possess understanding of the types of regulatory structures and practices which might succeed in stabilising a particular regime of accumulation, it is still unlikely that prevailing social and political conditions would automatically support and facilitate the straightforward introduction of these 'solutions'.

One of the reasons that 'stability' and 'harmony' tend to be so 'naturalised' in regulation-inspired accounts, however, is because the period of 1945 to the mid-1970s happens to have been one time frame within which state regulation of the economy succeeded in promoting sustained economic growth. As part of the Fordist-Keynesian state, the local state during this period crystallised into a particular form and performed a clearly identifiable role in the overall mode of regulation. In producing an ideal typical account of the shape of the local state during this time period, Goodwin and Painter (1996) argue that among the main features of the local state under the Fordist-Keynesian mode of regulation were: the pre-eminence of locally elected councils in the centralised delivery of services; the promotion of social democratic and wealth redistributive goals; the adherence to technocratic and managerialist structures; the underwriting the mass consumption norm required to sustain Fordist growth (provider of key aspects of the social wage and of 
services which could not profitably be provided by the private sector); and the shaping and implementing of the planning system.

Of course, the role of the local state in the regulation of Fordism has steadily diminished since the early 1970s with the demise of this particular regime of accumulation. Whilst analysts invariably speak of the rise of a de-regulated, flexible, disorderly, reflexive capitalist economy, what has come to replace the Fordist economic system is evidently a matter of some debate (Jessop, 1990, 1995). It should come as no surprise, therefore, that there is considerable disagreement about the extent to which a new mode of social and technical regulation has emerged too and, moreover, the extent to which the local state has been ascribed a new role in this regulatory apparatus. These reservations should not be taken to mean that new local state structures and functions are not discernible across the United Kingdom. Indeed, a number of decisive shifts in the role of the local state would seem to be occurring (Goodwin and Painter, 1996). Nevertheless, there would seem to be a geographical unevenness in terms of the degree of change. Further, whether the new structures and strategies of the local state amount to what might be referred to as a new role in an emerging regulatory system is highly debatable. For Peck and Tickell (1994), far from making a partial contribution to a new regulatory system, many developments in the local state in Britain might actually be serving to undermine the development of a stable new regime of accumulation.

Using the same ideal typical framework through which they attempted to characterise the structures and strategies of the Fordist local state, Goodwin and Painter (1996) provide a useful summary of the main shifts occurring within the local state today. Over the past two decades, the local government system in Britain has been transformed into one of local governance. Central to this shift has been a change in the philosophy of the local state. Instead of defining its role in terms of compensating or regulating the market economy, the local state is increasingly defining its role in terms of enabling the market. Among the many new developments that have taken place are: the growing importance of entrepreneurial and neo-liberal discourses, manifested most clearly in the commodification and privatisation of local government services; the growing importance of market mechanisms in the delivery of other services; the growing significance of local economic development policies as a legitimate policy area allied to the belief that the private sector must be the main broker of local development; and, perhaps above all else, the growing significance of central government quangos, parachuted into localities to by-pass the locally elected state as the agent of local governance in particular spheres.

A working hypothesis, which will be the subject of scrutiny in this paper, is that it is impossible to understand the nature of business politics in the contemporary British city without an appreciation of the manner in which recent transformations in urban governance are serving to catapult the state into new relationships with the business community. And it is around these interfaces with the state that one might expect business politics to concentrate. Certainly, this proposition has been at the heart of work done by Peck (1995) and Peck and Tickell, 1995). Peck's core thesis is that business barons are apparently being provided with unique opportunities at present to participate in the shaping of the trajectories of British cities. And this access to the political process has arisen as a consequence of recent changes in central state strategy vis-a-vis local government.

According to Peck, the rising importance of local business in the governance of British 
cities reflects an attempt by central government to create new institutional spaces within the city for capital to take advantage of. It is the pursuit by central government of new forms of neo-liberal institutions at the local level that has radically altered the political environment within which business interests can be represented; "the form of localism which is currently being witnessed... is very much a centrally orchestrated localism. The newly constructed local business elite exercise their influence in the main through locally based agencies established by, or networks afforded legitimacy by, central government." (Peck, 1995: 40) As Peck notes, "the argument presented here is that 'business interests' are currently being mobilised, given their form and presented with their function by the state" (Peck, 1995: 17).

In speaking of the new role local business barons seem to be playing, Peck (1995) points to development of a plethora of organisations such as TECs, LECs and UDCs across the 1980s and 1990s. These organisations are particularly interesting in so far as they pursue a deliberative strategy of incorporating only certain types of capital into the heart of city governance. The traditional, corporatist-inclined business representative organisations such as the CBI and Chambers of Commerce come to be replaced as the main representatives by more entrepreneurial forms of capital. It is those maverick capital, the "wheelers and dealers' in places, that are now given privileged access to the political process. For instance, they are now preparing inward investment strategies for localities, are drawing up retraining programmes, and are deciding upon the particular types of property investments localities most require. As just one facet of the current metamorphosis of the local state in Britain, the rise of the local quangocracy exemplifies how relations between the state and the local business community in British cities are currently evolving. It will be a task of this paper to assess the extent to which the entire package of change is serving to construct a new set of business political activities in turn.

\subsection{Research aims and the research approach}

There has been a tendency amongst regulationist accounts to operate with a taken-forgranted notion that business people will participate in the new institutional structures which are forming. Insufficient work has been done examining the actual response of the business community to the new opportunities for political involvement, which they have been provided with. To quote Wood et al. (1998: 16) "as such, the frameworks tend to pre-empt the origins and form of local business interests, the essential motivations for business involvement, and the complex interplay with central government sponsored 'probusiness agendas"'. This conclusion has led North et al. (1999: 6) to argue that there exists a need for an "examination of the processes whereby individual business people, as actors, decide to become involved in these new institutions of urban management and the extent to which they also create a common identity and collective business agenda to progress through these new institutions".

If indeed capital is less locally dependent in Britain, and if local dependence is a key attribute explaining capital's engagements in local business politics, then further analysis is required to account for why certain factions of capital DO engage with the state at the local level in Britain (and equally why some do not). A limited number of studies have been undertaken in a bid to address this question. These include Cochrane et al.'s (1996) 
study of the business sector's involvement in the Manchester Olympic bid, Imrie et al. 's (1995) study of local community responses to the Cardiff Bay development and UDC, Axford and Pinch's (1994) attempt to apply growth coalition theory to local development strategies in southern England, and Rogerson and Boyle's (1998) study of the role of maverick capitals in the formulation of Glasgow Development Agency's inward investment strategies.

Despite these studies, the paucity of a developed analysis of the response of business interests is in Wood et al.'s (1998) view still inhibiting greater theoretical understanding of the role of business involvement in the management and regulation of British cities. In turning to consider the conceptualisation of business interests and business interest formation in greater detail than hitherto, they mark out important new ground. Here, we wish to suggest a different path towards a similar goal; that of a more theoretically informed understanding of business involvement. Alongside theoretical reflection, we contend that understanding of the circumstances under which the business community does become politicised in British cities must also derive from more detailed case studies. We will present an empirical analysis of the political activities of leading property capitals within the major cities of Scotland in the spring of 1998. In so doing, we hope to further understanding of the kinds of responses this particular cohort of capitals are making to the raft of new state/property interfaces which are being created against the backdrop of the rise of more neo-liberal forms of urban governance.

In looking at how property mobilising agents have been politically active across a range of Scottish cities, we hope to foreground the importance of opening up analytic frameworks to the significance of beginning with capital. In particular, the freeing up of analyses from state-centred approaches offers opportunities for new research designs to be considered. There are, here, two ways in which the design of our study differs from the limited amount of work that has been carried out to date on the political activities of the business community in British cities. First, we choose to focus upon the political activities of capital in one sector only, property, and indeed our more specific interests lie with a selective group of actors within this sector, which we define as property mobilising agents. This is unique in so far as the majority of work done to date has tended to look at particular business clubs which have developed directly in response to state agendas. These business clubs tend, further, to involve a range of different capitals.

The predominance of studies of the public-private partnership type in our view presents a very narrow entry point. We interpret the interest in this work as deriving in part as a consequence of the desire of analysts to endeavour to find 'growth coalitions' of the North American variety in British cities. However, perhaps more importantly, this interest represents an epistemological position that reflects the state-centred thesis outlined above. That is, the analytic horizon is limited by the assumption that business political activities take place only within the shadow of the new neo-liberal forms of local governance. Furthermore, the only capitals that are examined are those that do participate (but see Imrie et al., 1995).

To be sure, our research itself attempts to ascertain the importance of new state structures in actually shaping business political activities. Our starting point, however, is one step removed from the state and begins with capital itself. By examining a range of companies who may or may not be involved in public-private partnerships, we hope to 
avoid the epistemological trap set by state-centred analysis. Our research design, therefore, reflects a more general interest in shifting the analytic basis of work in this area away from approaches which begin and end with the state, towards perspectives which, whilst using the state as an essential backdrop, nevertheless focus on the business community itself. In choosing to focus on one economic sector, we recognise that this too represents an imperfect starting point. We operate on the assumption that capitals in different sectors can be expected to generate different interfaces with the state because of their position within the overall capitalist system and therefore different sets of business political activities. This is not to suggest that all sectors are homogeneous. It is nevertheless to acknowledge that there can be expected to be greater intra-sectoral similarities than exist between different sectors of capital.

A second way in which our study differs from existing work is the fact that we have chosen to look at the political activities of companies across a number of cities. To date, analyses of business politics in the British city have tended to focus upon single city case studies. In some instances, a range of cities have been included, but this most often represents an attempt to compare discrete case studies rather than to examine how individual companies politic across the urban hierarchy. Again, this focus on single cities would appear to reflect both the need for analysts to find North American type growth coalitions in British cities, and the epistemological stranglehold which the statecentred view has in this area.

Our decision to focus upon Scotland relates in principle to the unique structure of the Scottish state system. In Chapter 2, we will demonstrate how the old Scottish Office model served to distinguish the Scottish political scene from its Westminster counterpart. With the existence of a distinctive state system which is serving to mediate how the national transfer of urban governance from Fordism to Post-Fordism is grounding itself specifically in Scotland, it makes theoretical sense to undertake analysis at this geographical scale. Moreover, the study took place in early 1998, well before the new Parliament was established (July 1999). We see our study as providing a useful benchmark for future work. It would, for instance, be fascinating to repeat this study to assess whether the political activities of property mobilising agents in urban Scotland have changed under the new constitutional circumstances.

Having outlined the novel aspects of the approach we have taken, it is now possible to specify the more immediate aims of the research project. By means of the first ever survey of the political behaviour of the largest property mobilising agents in Scotland, we set out to:

(a) assess the degree to which property mobilising agents are politically active in Scotland, gauging the importance of local level activity in relation to political activity at higher levels of government;

(b) examine the main channels through which property mobilising agents articulate their concerns to the state;

(c) ascertain whether there are any differences in the lobbying behaviour of different types of property mobilising agents;

(d) assess whether the recent shifts in the structures and strategies of urban governance have created new sites of political lobbying. 


\subsection{The focus on the property sector}

We have now outlined the broad approach we have taken to the topic and our principal research goals. Before we map out the structure of the remaining chapters, we wish to explain why we haven chosen to focus on the property sector. Our decision to look at property derives in part from the observation that property developers seem to be highly politicised in other parts of the world. For some commentators, this is to be explained by the fact that property typifies that type of capital that has been viewed as locally dependent. With its spatial immobility and tendency to economic illiquidity, property capital meets the conditions of local dependence which Cox and Mair (1988) argue to be so important. As noted already, the lack of such locally dependent capital in the United Kingdom, however, would appear to render this argument less relevant. Such a reading would be a mistake. It remains of interest to ascertain just how politically active this fraction of capital is even if it is not fully locally dependent.

Our decision to focus upon property politics derives, however, principally from our belief that there exists a raft on interfaces between the state and property sector and, as such, a study of property politics has the potential of allowing a variety of issues to be addressed which would be invisible if other sectors had been chosen. Partly because of the central role property plays in relation to the wider capitalist system (for example its capacity to cut across the various circuits of capital (Harvey, 1982, 1985)) there exist more areas of overlap between the property sector and the state than would be the case in other sectors, and certainly therefore more potential for conflict, friction, and political activity. There are surely few sectors that offer the same scope of coverage of potential patterns of business politics than property.

Drawing from a wide review of the literature, we wish to end this chapter by proposing a typology of possible state-property relationships in an effort to define the sets of interfaces which might be most significant in shaping property politics. Table 1 is offered as a heuristic tool to be referred to in the remainder of this paper. The table proposes the existence of five main categories of state/property relations, and in particular offers a 12-fold typology of the roles enacted by the state, which impinge on the property market. Clearly the nature of each interface will vary through time. For instance, one would expect the property development process to vary under different regimes of accumulation and therefore to set property into new relations with the state. Further, as noted above, as the state moves beyond its old Fordist-Keynesian structures and practices, one might expect the postures of the state to change, and old interfaces to metamorphose into different forms. The table is, therefore, pitched at a fairly abstract level, and surpasses the particular nature of interfaces produced under certain regimes of accumulation and associated modes of regulation. Further, not all the relationships cited are of immediate relevance to the local level and therefore to this paper. In the next chapter, an effort will be made to examine those interfaces, which are of particular relevance to the agents of urban governance in Scotland. The table serves, however, as a useful device for contextualising local state/ property interfaces within the wider context of all state/property interfaces.

\subsection{Structure of the paper}

The overall aim of this paper then is to use a case study of the political activities of 
Table 1

Key interfaces between the state and property market

Structures of governance

Constitutional and legislative arrangements (e.g. devolution, quangos)

Direct intervention in market

Subsidies and regional partnerships (e.g. Regional Selective Assistance, lottery funds)

Land and property ownership by the state

Occupier and tenant

Indirect market intervention

State investment in infrastructure (e.g. transport policy, environmental improvements)

Investment strategies (e.g. market intelligence, inward investment agencies)

Regulating property market operations

Fiscal policies (e.g. interest rates, monetary policy)

Protection of private property (e.g. police, fire, army)

Regulation of legal system of the property market (e.g. land and property ownership rights)

Legislation on design and land-use planning (e.g. green belt policy, development controls)

Ideological stance

Place marketing and external postures (e.g. hallmark events, cultural festivals)

Political culture and internal attitudes (e.g. bureaucracy, attitudes to development)

property mobilising agents in urban Scotland to further understanding of business politics in the city more generally. In focusing upon the political activities of capital within the property sector, and tracking behaviour across the Scottish urban hierarchy, this paper proposes a different approach from existing studies which have tended to focus upon the growth of public-private partnerships around the new institutions of urban governance. Whilst concerned with the extent to which the rise of post-Fordist forms of urban governance is serving to give shape to a new breed of property politics in the city, our decision to focus upon a sector-based approach represents an attempt to bring capital back into the centre of the equation.

The remainder of the paper is constructed around four chapters. First, in Chapter 2 we seek to isolate from Table 1 the state/property interfaces which are of greatest relevance in urban Scotland, and attempt to identify the ways in which the rise of post-Fordist forms of urban governance is active in reshaping the nature of these interfaces. This provides a context within which the third research question raised above, in particular, can be addressed. Given that ours is the first major survey of the political activities of mobilising agents to have been undertaken, in Chapter 3 we outline the principle methodological issues with which the study has had to contend. In Chapter 4 we then seek to profile those mobilising agents who make up our sample, and progress to a presentation of the core empirical results which have been produced. In particular, this chapter will seek to address the four research aims noted above. Finally, in Chapter 5, we will reflect upon the contributions which the paper has made and outline what we perceive to be the key theoretical directions for future research. 


\section{CHAPTER 2}

\section{State/property interfaces and changing trajectories of urban governance in Scotland}

In the previous chapter, it was argued that the way in which the British economy has been governed these past two decades has undergone transformation, as the rise to prominence of neo-liberal agendas has sought to transform the dominant mode of regulation based upon Keynesian demand management and the principle of the welfare state. We have noted that the question of the extent to which emerging new structures and strategies have served to steer the British state into new relationships with the business community has been raised. In turn, we have posited a further question as to whether recent changes have served to construct an environment within which a new breed of business politics might have developed. Prior to searching for an answer to these questions in the context of the property sector in urban Scotland, in this chapter we turn attention to the changing shape of urban governance in Scotland. In repositioning itself in new ways in relation to the business community, we are interested in assessing the extent to which the local state is now casting itself into a new trajectory in relation to the property sector specifically.

From our general typology of the key interfaces between the state and the property market portrayed in Table 1, we wish here to isolate out a number of the principal ways in which the local state in particular engages with the property sector. Further we wish to reflect upon ways in which the rise of post-Fordist forms of governance in urban Scotland is actively (or not, as the case may be) reshaping such local interfaces. We examine four of the five main categories identified in Table 1, covering a total of seven interfaces: the structures of governance (the rise of quangos); direct state intervention in property markets (including subsidies, the state as provider of property for the private sector, and as tenant/ occupier); indirect state intervention in property markets (infrastructure investment and investment strategies); and the state as a regulator (specifically under the local planning system). In focussing on only seven interfaces we do not wish to suggest that the remainder have no importance; only that in the local context their immediate relevance is more questionable.

Table 2 depicts the main (ideal typical) changes which might be expected in terms of these state/property interfaces as the local state evolves under the post-Fordist agenda. Of course, to the extent that the very concept of a post-Fordist form of governance has validity in the first instance, we bear in mind the idea that transformation is an ongoing process and is occurring unevenly across the country. It is hoped that by highlighting how a number of key interfaces between the local state and the property sector are currently changing in urban Scotland, we will be in a better position to address the third research aim outlined in the previous chapter; namely, how property mobilising agents are responding to the new agendas for urban governance. The primary purpose of this chapter, therefore, is to provide the essential context required for the analysis of the policy areas around which property politics is occurring in Scotland. 
Table 2

Key interfaces between the local state and the property market

\begin{tabular}{|c|c|c|}
\hline Interface & Fordist & Post-Fordist \\
\hline \multicolumn{3}{|l|}{ Structures of governance } \\
\hline & $\begin{array}{l}\text { Pre-eminence of } \\
\text { democratically elected local } \\
\text { state }\end{array}$ & $\begin{array}{l}\text { Rise of private sector-led } \\
\text { quango bodies }\end{array}$ \\
\hline \multicolumn{3}{|l|}{ Direct intervention } \\
\hline Subsidies & Limited role for local state & $\begin{array}{l}\text { Strategic pump- priming of } \\
\text { private market }\end{array}$ \\
\hline Land and property ownership & Large state holding & Privatisation of state holding \\
\hline Occupier and tenant & Limited state role as tenant & $\begin{array}{l}\text { Heavy state reliance on } \\
\text { private sector renting }\end{array}$ \\
\hline \multicolumn{3}{|l|}{ Indirect market intervention } \\
\hline $\begin{array}{l}\text { State investment in } \\
\text { infrastructure }\end{array}$ & $\begin{array}{l}\text { Significant public funding of } \\
\text { hard infrastructure }\end{array}$ & $\begin{array}{l}\text { Strategic state funding of soft } \\
\text { infrastructure for economic } \\
\text { growth }\end{array}$ \\
\hline Inward investment strategies & $\begin{array}{l}\text { Limited but nationalised } \\
\text { investment strategy }\end{array}$ & $\begin{array}{l}\text { Vigorous, localised and } \\
\text { competitive strategy }\end{array}$ \\
\hline \multicolumn{3}{|c|}{ Regulating property market operations } \\
\hline $\begin{array}{l}\text { Legislation on design and } \\
\text { land-use planning }\end{array}$ & $\begin{array}{l}\text { Comprehensive development } \\
\text { planning and land-use controls }\end{array}$ & $\begin{array}{l}\text { Pro-development and laissez } \\
\text { faire planning }\end{array}$ \\
\hline
\end{tabular}

\subsection{Changing structures of governance in urban Scotland}

For the benefit of readers unfamiliar with the Scottish scene, we start by contextualising the various structures of urban governance in Scotland within the wider Scottish state. Whilst many commentators have tended to represent the United Kingdom as a unitary state, it is more accurate to describe the constitutional arrangements which existed in 1998 as comprising a 'union state' (Mitchell, 1997). Whilst the union state is not federal, it is characterised, nevertheless, by the presence of different institutional structures in different parts of the country and often a degree of devolution of power from the centre. At the heart of the Scottish arm of the United Kingdom state is the Scottish Office. The Scottish Office is exclusively funded by Westminster in the form of a block grant, which in the 19971998 financial year amounted to $£ 14384$ million or approximately $28 \%$ of Scotland's GDP (Scottish Office, 1998a).

Prior to the establishment of the Scottish Parliament in July 1999, Scotland's interests have been represented at cabinet by the Secretary of State for Scotland whose responsibility has been to oversee the activities of the Scottish Office. At the time of writing (May 1999), this post has the same status as any other Minister responsible for a non-territorial or functional government department. Consequently, the Scottish Office is constrained and ultimately subordinate to the British Parliament at Westminster. The degree of influence it has "depends upon the issue, its political salience, the strength of the argument mustered, and the relative power of its ministers in government" (Mitchell, 1997: 409). Beyond 


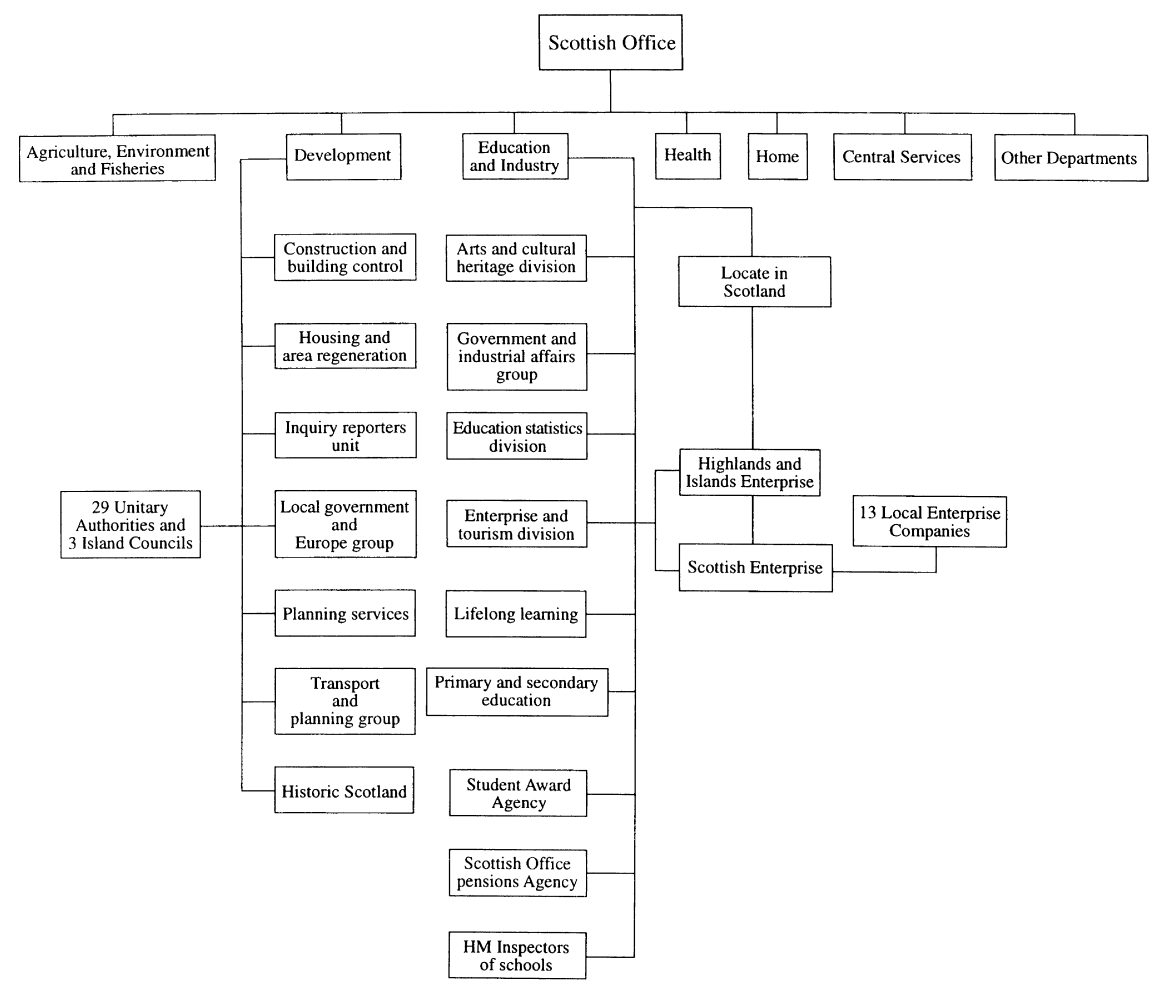

Fig. 1. Key aspects of the structure of Scottish office.

Central Services, the Scottish Office consists of five main Departments: the Scottish Office Agriculture, Environment and Fisheries Department (SOAEFD); the Scottish Office Development Department (SODD); the Scottish Office Education and Industry Department (SOEID); the Scottish Office Department of Health (SODoH); and the Scottish Office Home Department (SOHD).

Each of these departments in turn has many sub-divisions, including a number of Executive Agencies. Further, many of these sub-divisions and agencies are organised on a territorial basis, with varying degrees of autonomy from the centre. It is this battery of organisations and local offices which forms the backbone of the apparatus which governs the Scottish city. In the context of this study, our interest lies in the functions and responsibilities of two departments in particular; SODD and SOEID. Fig. 1 depicts the internal sub-divisions and Executive Agencies which fall under the control of these two departments.

The remit of the SODD is to administer a wide range of government policies related to housing and area regeneration, links with the EU-including the co-ordination of Structural Fund programmes (over $85 \%$ of the Scottish population is covered by Objectives 1,2, 3, and 5b) — roads and transport, the built heritage, and, most significantly, local government organisation and finance, and land use planning and building control. The current structure of local government was established by the Local Government etc 


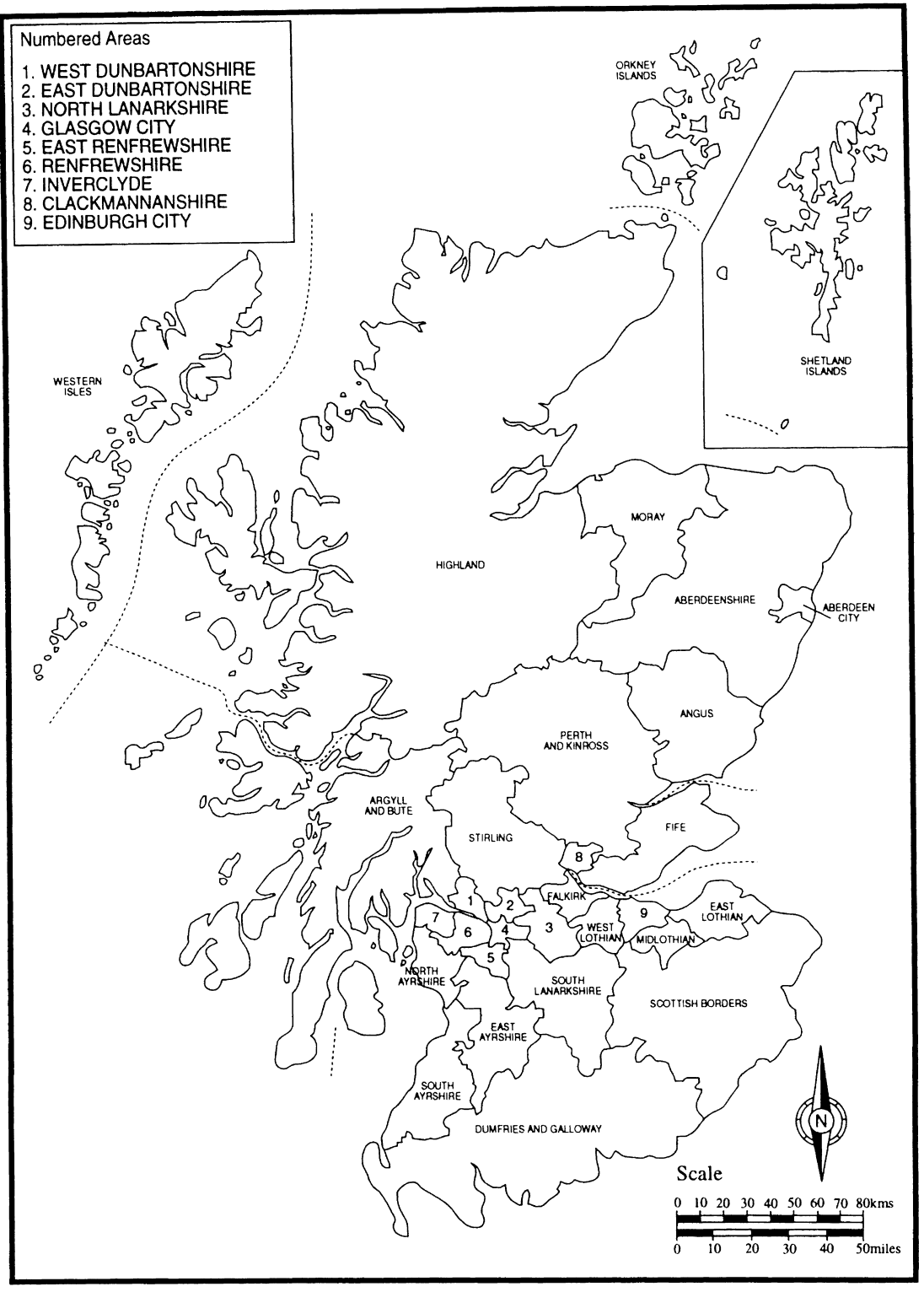

Fig. 2. Unitary authorities in Scotland.

(Scotland) Act 1994 and came into effect on 1 April 1996. The structure consists of 29 single-tier councils - replacing the 53 District and 9 Regional Councils established in 1975-and 3 Islands Councils (Fig. 2). The 32 councils are responsible for all services administered by their predecessors so that executive authority therefore now lies with single tiers of local government. Given our interest in urban Scotland, and based upon 
population density figures for each local government area from the data available from General Registrar Office (Scotland), the most urbanised local government units in Scotland are, in descending order, Glasgow, Dundee, Edinburgh, Aberdeen City, North Lanarkshire, and Renfrewshire.

In the literature reviewed above, it was argued that a defining feature of the Fordist mode of regulation was the pre-eminence of democratically elected local governments. The fact that the bulk of the SODD's expenditure of $£ 4280$ million in the 1997/1998 financial year was on the local government system (Scottish Office, 1998a: 173-174) would appear to be testimony to the fact that it remains a crucial player in urban Scotland. Whilst this observation cannot be overlooked, it would, however, be folly to ignore the increasing role which is being played by quango bodies, under the responsibility other subdivisions of the SODD and, indeed, of other departments. Such quangos embody the core dimensions of urban governance within the post-Fordist model (Table 2).

The key quango body which will be considered in this paper is Scottish Enterprise and its associated network of Local Enterprise Companies (LECs). Of the $£ 1945$ million spent through the SOEID in 1997/98, nearly $£ 450$ million was spent upon the Scottish Enterprise Network (Scottish Office, 1998a: 173-174). Scottish Enterprise's sister organisation, Highlands and Island's Enterprise, is responsible for the most rural and remoter parts of Northern Scotland and thus will not be considered further here. Scottish Enterprise emerged in 1991 as a replacement of the older Scottish Development Agency. As such, it has assumed the role of Scotland's leading economic development organisation. Macleod (1998) has been at the forefront of theorising the rise of Scottish Enterprise as an attempt by the Conservative government to establish a private sector-led, entrepreneurial national development agency in place of the more interventionist and Labour-inspired Scottish Development Agency model. As such, Scottish Enterprise can be read as an icon of the wider shift away from the Fordist-Keynesian compromise reported upon above. With Scottish Enterprise came an ideological shift towards privatism, and the role of the state was redefined to be that of enabling and lubricating the private sector.

In recognition of the different economic problems experienced by different areas of Scotland, Scottish Enterprise established a network of 13 Local Enterprise Companies (Fig. 3). With a few relatively minor exceptions, LEC areas overlap with specific combinations of local government areas and this should be borne in mind in the remainder of this paper. LECs function as private companies and are contracted by Scottish Enterprise to undertake specific local economic development tasks. Embedded within this relationship is a separation of the LEC from Scottish Enterprise, its location in a quasi-market, and its operation as a performance driven entity. This also means that the LECs have some autonomy to derive policy agendas of their own and, indeed, in some areas it is the LECs rather than Scottish Enterprise whom are responsible for devising and implementing new programmes and initiatives.

In the 1997-1998 financial year, Scottish Enterprise operated with a total budget of $£ 449$ million (Scottish Enterprise, 1998: 7). Table 3 indicates the division of expenditure across the 13 LECs. In terms of areas of activity, LECs are specifically contracted by Scottish Enterprise to improve business competitiveness (consuming $£ 51$ million of the $£ 449$ million for 1997-1998), to improve business start up rates (£25 million), to encourage inward investment ( $£ 11$ million), to improve exports ( $£ 13$ million), to provide 


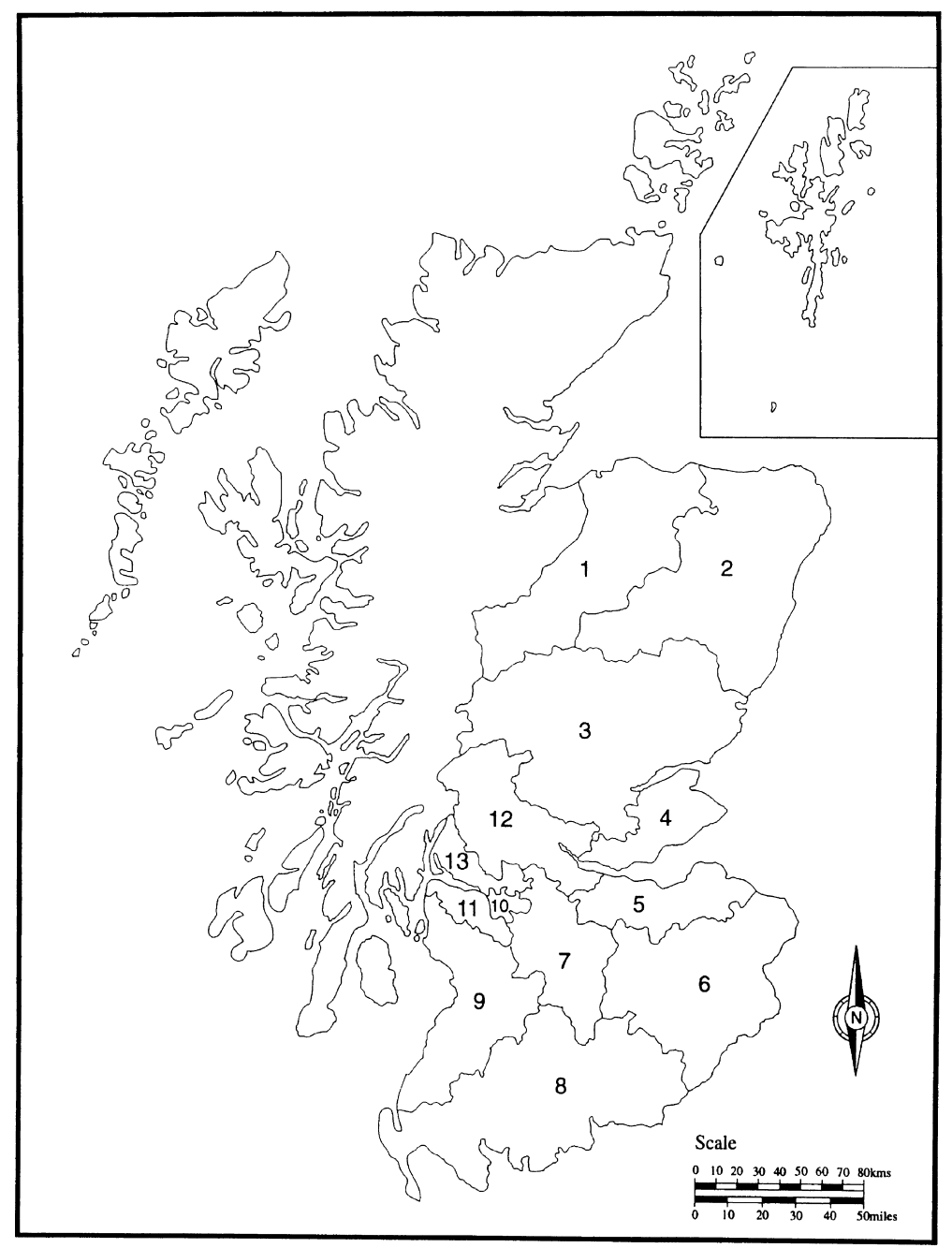

1 Moray, Badenoch and Strathspey Enterprise

2 Grampian Enterprise

3 Scottish Enterprise Tayside

4 Fife Enterprise

5 Lothian and Edinburgh Enterprise

6 Scottish Borders Enterprise

7 Lanarkshire Development Agency

8 Dumfries and Galloway Enterprise

9 Ayrshire Enterprise

10 Glasgow Development Agency

11 Renfrewshire Enterprise

12 Forth Valley Enterprise

13 Dunbartonshire Enterprise

Fig. 3. Local enterprise companies areas. 
Table 3

Scottish Enterprise expenditure 1997-1998 (Source: Scottish Enterprise, 1998: 7)

Expenditure (£)

$\begin{array}{lr}\text { Local Enterprise Companies } & \\ \text { Glasgow Development Agency } & 56 \text { million } \\ \text { Lanarkshire Development Agency } & 51 \text { million } \\ \text { Fife Enterprise } & 39 \text { million } \\ \text { Lothian and Edinburgh Enterprise } & 36 \text { million } \\ \text { Ayrshire Enterprise } & 26 \text { million } \\ \text { Renfrewshire Enterprise } & 25 \text { million } \\ \text { Scottish Enterprise Tayside } & 24 \text { million } \\ \text { Forth Valley Enterprise } & 22 \text { million } \\ \text { Grampian Enterprise } & 21 \text { million } \\ \text { Dunbartonshire Enterprise } & 16 \text { million } \\ \text { Dumfries and Galloway Enterprise } & 10 \text { million } \\ \text { Scottish Borders Enterprise } & 8 \text { million } \\ \text { Moray/Badenoch/Strathspey Enterprise } & 2 \text { million } \\ \text { Scottish Enterprise Network } & \\ \text { Scottish Enterprise Central } & 77 \text { million } \\ \text { Training Allowances } & 36 \text { million } \\ \text { Total } & 449 \text { million }\end{array}$

training ( $£ 128$ million), to provide physical business infrastructure ( $£ 113$ million), and to enhance social inclusion ( $£ 41$ million) (Scottish Enterprise, 1998: 6).

As the key institution behind the local economic development of Scottish cities, and as icons of the new post-Fordist state, LECs have served to generate a myriad of new state/ property interfaces. The most important of these will be outlined below. First, it is essential to note that, with the rise of LECs, the capacity of the private sector to gain decisionmaking power has increased. LECs are controlled principally by private sector boards, which are, in part, selected by the Secretary of State for Scotland, but also recruited by a process of self-selection. In line with the Thatcherite ethic of empowering local business elites, and in particular recruiting local mavericks with entrepreneurial flair and drive onto key structures of urban governance, LECs are governed by key figures in the local business community (Hayton, 1992; Peck, 1995; Macleod, 1998). In consequence, from the perspective of the property sector, the LECs represent sites of power over which they might have direct influence. To the extent that leading property players are in the in circle' in their respective cities, they have an opportunity not just of having their voices heard by sympathetic ears, but also of actually taking a seat at the heart of power themselves.

At one level, these local enterprise bodies are taking key governance roles out of the provenance of the democratic local state. Further, their importance is increasingly being supported by the local state itself, which now appears to recognise that it is only through forming coalitions with a range of partners, including LECs, that they can hope to build sufficient capacity to make a difference to life in Scottish cities. Such coalitions may offer the opportunity for some democratic accountability to be imposed on these quangos. One 
example of this shift in attitude within the democratic local state can be witnessed in the Glasgow Alliance organisation. This umbrella organisation, which includes representatives from Scottish Homes, Glasgow Development Agency, and Greater Glasgow Health Board, is chaired by the local council and now claims to be the central 'driver' behind the city. It is currently attempting to formulate a plan for the city, which will give a sense of coherence and steerage to the action programmes of the major public bodies in the city, and to avoid duplication of effort and conflict of interests. Glasgow Alliance, although only currently finding its feet, is widely recognised by the movers and shakers in the city to bear witness to the growing recognition that local governments in Scotland are now willing to open up their decision-making structures and to embrace the local quangocracy in order to build capacity.

\subsection{Direct intervention in the property market}

Beyond changes in the actual structures of governance, there have been important shifts in the practices of governance. Amongst the most significant have been shifts in the ways in which the state directly intervenes in property markets. The literature would suggest that with the rise of post-Fordism greater emphasis should be placed on the role of the private sector in the provision of property. Certainly evidence in urban Scotland suggests that the local state is privatising its property holdings, and is at most intervening only in the market at times of failure. In terms of the provision of commercial property the main role of the state is to lever private investment. Further, the state is now relying on the private sector to provide the infrastructure it itself requires as part of its remit as a service provider.

\subsubsection{Privatisation of property holdings and the turn to pump priming}

Whilst the Scottish Development Agency played a central role as a provider of commercial property during its existence from 1975 to 1991, local authorities too have historically played a significant role. Whether it be in terms of the construction of industrial estates, the provision of offices for commercial renting or the ownership of vast tracks of retail outlets, local authorities in urban Scotland have historically made fairly heavy capital injections to improve the built environment for local economic development. Such intervention has been undertaken in the belief that it is the state's responsibility to ensure that the property requirements of an expanding economy are met. Not only has the private sector not been encouraged to develop, but on some occasions the operation of the private market has actually been crowded out by public sector property development.

Probably from as early as the mid-1980s, and certainly following the birth of Scottish Enterprise, there has been a decisive shift away from this position. Certainly at a time when local authorities are seeking to enlist the help of the of the private sector to meet their own needs (through the Private Finance Initiative), it is not surprising that they are also turning towards the private sector to create suitable built environments for economic development. At one level, this transition is witnessed in the privatisation of public property. Whilst New Town Development Corporations and Scottish Enterprise have led the way in terms of the privatisation of large sections of their property portfolio, local authorities have not been far behind, and have sought, whenever possible, to offer selective property holdings to private interests. At another level, however, and in 
recognition that the operation of the private market might require some lubrication, there has grown a more strategic form of public sector intervention, which seeks to lever private investment. As evidenced in the role of Glasgow City Council in attracting property capital into the merchant city area of Glasgow in the 1980s, or more recently the role of the state in the construction of the new South Gyle shopping centre in Edinburgh, local government still does continue to play a part in public efforts to stimulate the private market.

It is, nevertheless, in the activities of the LECs that pump-priming of the private property sector is most evident. The LECs normally only involve themselves in property development in circumstances of market failure and where there is a significant strategic benefit. Even then, this involvement is overwhelmingly on a partnership basis with the private sector. For instance, LECs may reclaim land, decontaminate land, and provide certain site assembly functions, only if the private sector will take responsibility for its development. The bulk of the $£ 113$ million spent across the Scottish Enterprise Network on physical business infrastructure in the 1997/1998 financial year was to this end.

The transformation in urban governance from state provision of property to the privatisation of property and the increasing significance of public sector leverage of private investment is clearly serving to create new types of relationships between the state and the property sector. To argue that the governance of urban Scotland is now driven by the fundamental goal of liberating and lubricating the property market, however, would be to stretch the argument too far. It would seem that the workings of the property market are generating concerns for the state and that, in many instances, such concerns are demanding roles more akin to older forms of market regulation and intervention. Market failure means more in this context than merely the lack of provision of property in relation to the needs of the local economy. It might alternatively be conceived, as the failure of the market to deliver the kinds of property developments demanded by local state officials. As such, the state is driven to shape development to bring it into line with state agendas.

In some respects, it is the presence of uneven development across the Scottish LECs and indeed within the Scottish LECs which is causing greatest concern. Conclusions drawn from two recent official reports point to an increasing concern about the geography of LEC involvement in pump priming. First, at the national level, EKOS (1998) recently published a Scottish Enterprise commissioned report examining the provision of advance factories for inward investors in Scotland. This report argued that four types of LEC area exist in Scotland. Type A LECs (Lothian and Edinburgh Enterprise, Lanarkshire Development Agency, and Fife Enterprise) are locations of large amounts of diverse inward investments and have a vigorous private property market leading to relatively large reserves of advance factories. Type B LECs (Moray, Badenoch \& Strathspey, Scottish Borders Enterprise, and Dumfries \& Galloway Enterprise) are, in contrast, largely rural in character, with very low levels on inward investment and a negligible private property market. Although having few reserves of advance factories, these areas would appear to have few requirements for such property. Type C LECs (Forth Valley Enterprise, Dunbartonshire Enterprise, Renfrewshire Enterprise, Ayrshire Enterprise, and Scottish Enterprise Tayside) are locations which have seen a modest amount of inward investment, including a small number of large projects, but which suffer from a relatively weak property market. They are in need of advance factory provision. Finally, Type D LECs (Glasgow 
Development Agency and Grampian Enterprise) are locations with high levels of very specific types of inward investment (financial services in Glasgow, energy in Aberdeen). Whilst Aberdeen will continue to rely on the energy sector, and will continue to be relatively well endowed with the necessary advance factory spaces, Glasgow is seeking to become a Type A LEC and does require to augment its existing 'strategic sites strategy' with another phase of new site development which might make it better equipped to receive a greater variety of inward investments.

In commissioning the report, Scottish Enterprise specifically requested advice on how a more integrated approach to advance factory provision could be co-ordinated across Scotland. To this end, EKOS recommended that cognisance be given to the above fourfold typology, with strategic pump-priming initiatives being devoted to areas of greatest need. For instance, LECs should only enter into public-private partnerships in areas with less that three years existing supply of advance factories and where there is clear evidence of market failure. It is clearly debatable whether LECs will be prepared to take such a national strategy on board, but what this EKOS report does illustrate is that coping with the uneven geography of the existing demand and supply base is on the Scottish Enterprise agenda.

Second, at a more local scale, Ryden (1998) published a report examining trends in office development and location in Scotland. The specific remit of the report was to examine whether new trends in office location were occurring across Scotland in the light of the revisions to the 'Use Classes Order' permitting office development on land zoned for industrial development which took effect in 1989. The concern was that this change in planning policy had triggered out of town office developments in business parks surrounding settlements. The report noted that whilst not occurring to the same degree as in England, Scotland was witnessing a drift of new office developments to out of town locations, particularly in the old Lothian and Central regions. Further, "continued development in off-centre locations.... will leave behind a growing urban regeneration challenge in the form of obsolete offices, particularly those of 1960s/1970s vintage" (Ryden, 1998: 37). Given government policy towards regenerating the city, developing brownfield sites, and producing more sustainable transport plans, the report recommended that "public sector authorities in relevant areas should be encouraged to consider mechanisms, including compulsory purchase, selective financial assistance, and site assembly (with associated infrastructure), whereby in-town office development opportunities could be created to match those out of town" (Ryden, 1998: 37). Once again, LEC intervention is being encouraged in a spatially specific way. The aim may be to lubricate the market, but lubrication is being undertaken within a specific political context.

\subsubsection{From property owner to tenant}

Aside from changing its role in the provision of property, the local state is also undergoing a metamorphosis from property owner to tenant. Indeed, perhaps the most recent and most significant example of how the post-Fordist local state is ushering in new state/ property interfaces is the growing significance of the Private Finance Initiative (PFI). The PFI was launched by the British Government in November 1992 with the basic goal of increasing the role of the private sector in the provision of the infrastructure required by public services (Gallimore et al., 1997). Despite its somewhat stuttering start, and the 
change in government from Conservative to Labour, it remains at the forefront of current government policy. Indeed, it emerged as a major political football in the run up to the Scottish Parliament with the Scottish Nationalist Party threatening to abandon it if they got to power. Although some senior figures in the Scottish Labour Party are against the concept, it is likely to remain a key and active policy for the foreseeable future.

Against the backdrop of an increasingly run-down public sector capital stock, further predicted decreases in feasible public sector capital expenditure, and the prevalence of a climate of privatisation within the public sector, the PFI represents the preferred route of financing better buildings for the provision of public services. In essence, the private sector is being invited to take over the construction and maintenance of new hospitals, education establishments, airport buildings and so on. In so doing, the private sector takes on the risks which the public sector would otherwise have to carry (site acquisition risk, planning approval risk, design risk, construction risk, maintenance and facility management risk, occupation-demand risk, obsolescence risk and residual value risk). The public sector, meanwhile, assumes the more risk aversive, but perhaps also least profitable, role of sitting tenant for an agreed period of time.

Whilst the PFI remains at a very early stage, it is clear that the UK government has grandiose ambitions for it. According to the government, there exist over 1000 possible PFI projects across the UK with a capital value of $£ 25$ billion, and estimated cumulative service costs of $£ 40-60$ million (present value) (Gallimore et al., 1997). According to figures from the Scottish Office (personal communication 26 October 1998) a total of 11 projects have already been completed (capital value of $£ 56.9$ million), 14 projects have already been signed (estimated capital value of $£ 737.5$ million), 19 projects have issued tenders or at the negotiation stage (estimated capital value $£ 727.1$ million), 3 are currently being advertised (estimated capital value of $£ 17.7$ million) and 12 projects have been designated as having PFI potential (estimated capital value of $£ 712.5$ million). Further, the current and proposed PFI would seem to have a widespread geography with all major urban centres having an interest. For example, the location of projects, which have been completed or signed to date, include Glasgow, Edinburgh, Aberdeen and Dundee, as well as Perth, Law, Falkirk and Inverness. PFI would seem to be an issue, which is touching the built environment of all major conurbations in Scotland. To the extent that the PFI will develop into the major vehicle for the delivery of public sector infrastructure, it clearly has the potential to shape the context within which local governments operate. Particularly, local governments, a major consumer of public sector infrastructure, will be required to develop whole new ways of relating to the property sector as a tenant or customer.

\subsection{Indirect intervention in the property market}

Broad local economic development strategies pursued at the local level also have served to cast agents of urban governance into new relationships with property companies. In this context, our interest lies in those general strategies that attempt to improve the economic environment within which property companies operate and, as such, impinge upon the fortunes of these companies in an indirect way. Certainly there has been a marked growth in the significance given to local development initiatives by local governments in Scotland. Particularly, it would appear to be in the area of upgrading the environment and 
image of cities to attract inward investment and tourists that local government is most active. Glasgow is clearly one city which has vigorously embraced the place-marketing ethos. Through campaigns such as Glasgow's Miles Better, the Glasgow Garden Festival 1988, the European City of Culture event 1990 and, more recently, the British City of Architecture and Design 1999 celebrations, Glasgow has attempted to upgrade its soft infrastructure in order to stimulate economic regeneration. Beyond Glasgow, most of the other main urban centres in Scotland have followed suite. Whether it be in terms of Edinburgh's new look Summer Festival or its Hogmanay Party, Aberdeen's hosting of the Tall Ships event, Dundee's parading as City of Discovery, Perth's claim to be the Fair City, or the various television promotions pursued by Cumbernauld, East Kilbride, and North Lanarkshire, it is clear that place marketing and civic boosterism have been central devices used by local governments in Scotland across the past two decades. And, it is also clear that perhaps more than any other business category beyond tourism, property developers have benefited most from this new area of state activity, and have the greatest stake in it.

Whilst the relatively small amounts spent through local government on local economic development projects forbid one from speaking about the much lauded transformation from urban managerialism to urban entrepreneurialism (Boyle and Hughes, 1994; Wood, 1998), it would be a mistake to ignore the increase in activity in this area. Nevertheless, local economic development initiatives are more clearly the provenance of LECs in urban Scotland. Through a variety of interventions in the general economic environment within which property companies are operating, LECs are serving to exert important influences on their degree of success. Two examples can be cited here. First, without question one of the most significant functions performed by LECs is that of training and re-training the local labour force. As noted above, across the Enterprise network, this role accounts for a major share of total expenditure. For property companies, this role is significant for two reasons. First, it plays a part in helping companies (both indigenous and inward investors) grow and therefore develop greater property needs. Second, given that some of the qualifications on offer are in the building trade or entail more generic skill acquisitions like IT skills, property companies have something to gain from this area of LEC activity.

A second area in which LECs impact upon the property market in a general way is through their inward investment strategies for cities. With primary responsibility for devising inward investment strategies for their area, LECs have an influence on the structure of property requirements within the city and thus upon the relative fortunes of different fractions of property. For instance, Glasgow's key inward investment strategy, which currently focuses upon attracting call centre operations, computer software companies and financial services companies, clearly has different implications for office developers and those developers who provide industrial premises. As such, the inward investment strategies of LECs can be expected to generate a variety of state/property interfaces, with only a select group of property capitals receiving most benefit (Table 4).

One particularly interesting role played by the LECs in terms of encouraging inward investment is that of providing market intelligence on available sites. Scottish Enterprise has, for instance, been working with the Department of Land Economy at the University of Paisley to create the Scottish Property Network. At the heart of this network is a database of properties across Scotland classified by a variety of different criteria (e.g. vacant/occupied, 
Table 4

Key inward investment sectors by LEC (July 1998) (Source: EKOS, 1998)

\begin{tabular}{ll}
\hline Glasgow Development Agency & $\begin{array}{l}\text { Financial services, call centres, software, biotechnology, } \\
\text { opto-electronics }\end{array}$ \\
Lanarkshire Development Agency & Electronics, healthcare, call centres, engineering \\
Fife Enterprise & Electronics, call centres \\
Lothian and Edinburgh Enterprise & Electronics, financial services \\
Ayrshire Enterprise & Electronics, call centres, software, aerospace \\
Renfrewshire Enterprise & No key sectors \\
Scottish Enterprise Tayside & Oil and gas, food, engineering, biotechnology, call centres \\
Forth Valley Enterprise & Petro-chemicals, electronics \\
Grampian Enterprise & Software, bio-technology, oil and gas \\
Dunbartonshire Enterprise & No key sectors \\
Dumfries and Galloway Enterprise & Plastics, forest products, tourism, food \\
Scottish Borders Enterprise & No key sector \\
Moray/Badenoch/Strathspey Enterprise & Tourism, food, call centres, manufacturing \\
\hline
\end{tabular}

lease dates, potential usage, cost per square foot, utilities available, and location). To date, this database has offered a reasonably comprehensive list of industrial properties, with some office and retail properties also included. With the exception of Aberdeen, the database has a wide geographical coverage of the whole Scottish Enterprise Network. Individual LECs now have access to this database and are making use of it to ease companies in their search for suitable premises. Not only does this help inward investors find the right property quickly but it also increases the efficiency with which the property needs of new and expanding indigenous firms can be realised.

\subsection{Planning and property development}

Whilst local governments exercise a reasonable degree of autonomy in relation to planning issues, the Scottish Office, through the SODD, can be seen to impinge upon local government planning processes in a number of ways. Perhaps the most important control placed upon local planning authorities is their need to adhere to the National Planning Policy Guidelines (NPPGs) (formally National Planning Guidelines). These represent not only official interpretation and portrayal of the various legislation, which provide a framework for planning in Scotland, but also outline the planning priorities and agendas that the Scottish Office wishes to set. At present a total of thirteen NPPG papers have been produced. Of particular interest in the present context is NPPG 1 (Scottish Office, 1994) which sets out the most fundamental characteristics of the planning system in Scotland, NPPG 2 (Scottish Office, 1993) which defines the methods this system should adopt in dealing with business and industry developments, and NPPG 8 (Revised) (Scottish Office, 1998b), which provides guidelines on planning issues associated with town centres and retailing development.

Across each NPPG is the planning architecture defined in NPPG 1. At its core are the concepts of Development Plans, Structure Plans and Local Plans, each of which in their own respects provides a framework within which planning decisions should be made. Development Plans represent overarching planning frameworks for different regions. 
Although produced at present by unitary authorities (or in some cases combinations of unitary authorities) each plan can only be finally accepted (at the time of writing) with the approval of the Secretary of State. Development Plans are intended to: provide a strategy to guide the location of development for a period of 10 to 15 years; document the various opportunities for developments which would suite particular areas; define the control standards to be imposed upon different developments; and highlight how development can best be accommodated without jeopardising desirable natural and urban environments.

Development Plans consist of Structure and Local Plans. Structure Plans are formulated in the recognition that planning often needs to be undertaken at a 'regional scale'. They comprise broad statements concerning strategic land use planning and as such set down a coherent framework for the production of local plans. At present, the 32 unitary authorities across Scotland are being asked to submit revised Structure Plans, either individually or as part of a collective, and some are already at public consultation stages. Local Plans express specific planning policy guidance and advice for particular localities. Local Plan areas do not coincide with unitary authority areas and it is usual for the latter to produce a number of plans for smaller internal units. At the end of May 1998, Scotland had 237 Local Plan areas, with 212 plans formally adopted, 2 at the public local inquiry stage, 10 finalised, 8 at the draft stage, and 4 started (Planning Bulletin, 1998). Unlike Structure Plans, which are expected to have relatively long life expectancies, Local Plans are required to be revised and/or revalidated every five years and thus their accommodation to the new Structure Plans, which are emerging, is expected to be ongoing.

The growing significance of pro-development objectives tempered by the continued significance of the basic planning framework and the regulatory and control functions of planning can be seen in other NPPGs. NPPG 2 specifically deals with industrial developments but it also implicitly concerns itself with office construction. At a general level, NPPG 2 requires that Development Plans explicitly address a number of key economic issues. For instance, Structure Plans are required to "allocate land to provide for a marketable supply of general industrial and business class land throughout the period", to "justify the allocation by reference to the overall strategy and indicate the spatial distribution of the supply, taking into account the full spectrum of industrial and business needs", and to "indicate and clearly justify the priority, if any, to be given to particular types of economic development". Further, Local Plans are instructed to "identify sites in conformity with the Structure Plan applications", "include policies for determining development proposals for sites not in marketable supply", and to "state the means by which new sites will be brought forward as identified sites are developed". Significantly, Local Plans are also requested to encourage the redevelopment of brownfield sites as opposed to greenfield construction wherever possible, and to consider introducing Simplified Planning Zones as a promotion device. Beyond these somewhat general guidelines, NPPG 2 identifies a number of sites deemed to be 'National Sites' by virtue of their significance to national economic development. Four types of national sites are identified: large, single user high amenity sites; medium sized industrial sites; large industrial and business sites; and large petrochemical sites. Development Plans are required to adopt specific policies in relation to each of these types. Finally, given the potential for 'mega-projects' to impact upon the remainder of Scotland, NPPG 2 instructs that all proposals requiring greater that 100 ha of land must be authorised by the Secretary of State. 
NPPG 8 (Revised) also illustrates the desire to channel development in particular directions. It provides a series of policy guidelines in relation to town centres and retailing. By retailing is meant everything from new regional and district shopping centres, through retail parks and factory outlet centres to commercial leisure centres, superstores and supermarkets, and restaurants and pubs. Following three decades of out of town retail development, and the much discussed demise of the vitality and viability of the traditional town centre, NPPG 8 (Revised) represents a dedicated planning approach to the concentration of new retail developments in, and the rebirth of, conventional town centres. To this end, its key concept is the notion of a sequential approach. Future development (to the extent that it is in the interests of the area and Scotland, in the case of regional shopping centres) should first be located in existing town centres, should consider edge of town locations if relevant sites are not available, and should only be located out of town as a last resort and providing a number of stringent criteria are met. To this end, Structure Plans are instructed to "set out the policy for supporting and enhancing town centres, including an assessment of how far the existing town centres might be able to meet the demands for new shopping floorspace and other uses", and "reflect upon the criteria set out in this guideline against which retail and commercial leisure development proposals outwith town centres should be assessed". Local Plans, meanwhile, are required to "aim to safeguard and support existing town centres and other retail facilities such as local centres and village shops, where they are serving the local community well", and "identify sites, including those suitable and available within a reasonable timescale, for new retail and commercial leisure developments, within town centres, and, if appropriate at the edge of centre".

The fact that the present system of land use planning has persisted across the last twenty five years is indicative that, at least in terms of planning, no clear transition from Fordism to post-Fordism can be detected in urban Scotland. In part this apparent lack of transition reflects the under-developed ways in which the post-Fordist mode of regulation has been applied to local planning. Indeed, there is a dearth of accounts, which explore the new characteristics, practices and functions to be anticipated, even theoretically, under a postFordist model. In Goodwin and Painter's Goodwin and Painter (1996) account of the ideal typical form of post-Fordist local governance, for example, there is not even specific engagement with planning. What has been suggested as representing such a post-Fordist planning system is one which involves "the creation of arm's-length organisations for a variety of tasks from hearing planning appeals to disposing of waste; the emphasis of responsiveness and flexibility in all planning decisions; [and] the attack on planning as an activity under professional control operating within a state bureaucracy" (Rydin, 1998: 351). From the above discussion, it is clear that the existing planning system in Scotland falls far short of even these basic characteristics, not only in terms of its architecture but also its practices.

In 1998, the Scottish Office produced a comprehensive review of development planning in Scotland (Scottish Office, 1998c). This review is interesting in so far as it might reasonably be expected that any shift in planning philosophy would be detected from its recommendations. The review argued that whilst the basic legislative framework for planning remained sufficient, the practice of Development Plan proposal, implementation, and evolution required modification. In some ways, proposed changes would seem to 
reflect a growing pro-development agenda for planning. For instance, among the recommendations reached were:

(a) the entire preparation time of Local Plans, and the time taken by the Secretary of State to authorise Structure Plans, requires to be greatly speeded up. Developers, for instance, demanded that published timetables be backed up by sanctions from central government, not least in order to get around the problem of pre-maturity being cited as a reason for refusal of planning permission;

(b) plans are too closely associated with local authorities and are largely ignored by key resource agencies. Whilst planning authorities desired to keep their roles as central owners of plans, the review recommended that ownership be widened to include local development agencies and developers among other groups. This would ensure a wider sense of legitimacy;

(c) the preparation of plans should be an ongoing processes, rather than a once and for all exercise. Not only will this improve the speed of plan preparation but it will also ensure that plans can be modified in the light of short term changes in conditions;

It would be disingenuous, however, to conclude that something fundamental was happening to the planning system in Scotland on the basis of this report as it too raised concerns about including more voices from the community in planning decision making and ensuring that all local plans had effective public local inquiries. By advocating a retention of the existing planning architecture, this review further points to the limited possibilities which exist for the development of a full-blown post-Fordist turn in planning regulation of property markets by the Scottish state.

\subsection{Conclusion}

In this chapter, we have chosen to focus upon seven of the most important sites of contact which exist between the state and the property sector in urban Scotland. Drawing upon wider literature on the restructuring of the local state in the United Kingdom across the past two decades, we have enquired into the kinds of transformations in the nature of these interfaces that might have been expected in urban Scotland specifically. From an examination of evidence of change on the ground, we have attempted to build a picture that we hope will prove useful to the reader in the interpretation of our survey results to follow. It is our central argument that whilst the rise of post-Fordist forms of urban governance can certainly be detected in Scottish cities, and whilst this has served to create new local state/property interfaces, it would be a mistake to exaggerate the extent to which the state has turned away from market regulation and intervention. Interfaces between the local state and property consist of a complex mixture of old relationships, old relationships modified to cope with new circumstances, as well as entirely new sets of connections. It is undoubtedly best, therefore, to conceptualise property politics as developing amidst a maelstrom of change, rather than reflecting a clear-cut philosophical shift in the governance of Scottish cities. Change is a messy phenomenon and in 
many senses the local state continues to function in its traditional role; as a regulator of property markets, and as an agent of intervention, trying to direct, shape, and even at times control the ways in which the property market operates for political ends. 


\section{CHAPTER 3}

\section{Research design: identifying and surveying property mobilising agents}

Having identified the context within which this study is placed-the shift in the forms of local governance in Britain in general and Scotland specifically-here we turn to consider the survey which forms the backbone of the remainder of the paper. Given that this survey represents the first major effort to reveal patterns of property politics in urban Scotland, we develop and justify the research design employed at some length. We start with an outline of the key group of property players that comprise the specific focus of the study. As noted in Chapter 1, we have chosen to refer to these types of players as property mobilising agents, and we begin by positioning these agents within existing typologies. We then turn attention to the methodological considerations which have been addressed in developing and undertaking the survey. These considerations are offered, not only as a backdrop to the results considered in the next two chapters, but also as a contribution to help navigate future work in this area.

\subsection{Positioning property mobilising agents}

Broadly speaking there exist two overarching approaches to the production of typologies of property companies. At one level research has focussed on the wider position of property within circuits of capital. Therein typologies have been constructed within the terms of the ultimate origins of capital; that is, the particular circuits from which capital derives. Whilst not mutually exclusive, a second literature has developed recently which, being aware of the wider context, nevertheless seeks to privilege the battery of mediating institutions which serve to ground capital in particular places at particular times. Our focus on property mobilising agents sits more comfortably within this latter, institutional approach.

\subsubsection{Property capital and players}

In geography, the legacy of Harvey's (Harvey 1982, 1985) reading of the location of property within the capitalist system remains strong. For Harvey, property had to be linked to both primary circuit needs - for example, development for expansion of productionand to the development of the built environment arising from capital switching to the secondary circuit as a 'safety mechanism'. Harvey's notions have been extended further in the 1990s with, e.g. Leyshon and Thrift's (1997) recent work which explores the relative autonomy of financial circuits from other capital circuits. Their argument points to the logic of considering that some capital invested in property development may be derived from financial circuits, which have a high level of separation from the primary and secondary circuits discussed by Harvey.

By locating property within the wider capitalist system, some authors have argued that the property development process can be dissected into a series of fractions of capital, each occupying a different structural position within the overall system. Barras (1979) has suggested, for example, that four types of capital can be identified in this way: commercial (the development company); financial (investing and funding institutions); 


\begin{tabular}{|l|l|l|l|l|}
\hline \multicolumn{3}{|l|}{ PARTIES IN THE DEVELOPMENT PROCESS } \\
\hline Clients & & & & \\
\hline & & Professional advisers & $\leftarrow---$ & Planning authorities \\
\hline Funders & $---\rightarrow$ & & $\leftarrow--$ & \\
\hline & & & & \\
\hline
\end{tabular}

Fig. 4. Representing the property development process.

landed (owners) and industrial (construction companies). Whilst useful insofar as it attempts to ground typologies within the wider capital accumulation process, Barras' framework is, however, limited in that it fails to appreciate fully the further divisions of each category. Consequently this approach has been viewed as tending to elevate structural forces working beyond the built environment over a focus on individual actors, and at the same time giving hegemony to capital rather than, to say, political and cultural systems. King (1989) notes that, whilst Harvey recognises a role in the construction of the built environment for 'mediating institutions', in focusing mainly on the deeper structures of capital "there is little room in the theory for the role of individual agency, nor even for consideration of how mediating institutions came about in the first place" (King, 1989: 452).

More sophisticated attempts have been made, nevertheless, which, while starting from the circuits of capital perspective, have progressed to a more detailed understanding of the various structures through which property development is played out. Drawing on Malone's (1985) analysis of those capitals involved in property development in Dublin, Bryson's (1997) recent paper illustrates how different types of capital can be related to separate actors or agents in the property development process. For instance, Bryson represents the position of the property developer between four other sets of interests: the financier and money markets; the landowner and the land market; the investor and tenant and the property market; and the constructor and industrial capital. As he notes "each type of capital competes for a share of the development profit generated from each property development; their relative shares are determined by their relations within the overall process of production" (Bryson, 1997: 1441). In this portrayal, the developer has a pivotal role mediating these interests to ensure that development of a property actually takes place.

Others, adopting a perspective from within the building profession, have advocated a slightly different set of relations. Isaac (1996), for example, has conceived of the parties involved in the development process as shown above in Fig. 4. For him, the different capitals involved in the development process are encapsulated within the 'clients' and 'funders' boxes. Clients, a diverse range of actors, including developers, landowners, and investor/traders, represent a different form of capital from the providers of short-term and long-term funding (the funders). The other groups are those whose roles involve the grounding of this capital and the regulation of the development process. 


\subsubsection{Institutional perspectives}

Some authors now recognise that relating the roles played by those involved in the property development process to their wider positions in circuits of capital is not only difficult, but is also, perhaps, misplaced. An alternative perspective, arising in part from critiques of such neo-Marxist theses, argues that "the built environment is the result of the relationships between agents and institutions within the local economy on the one hand, and with regional, national, and international financial and development interests which are influenced by structural factors on the other hand" (van der Krabben and Lambooy, 1993, 1384). This alternative, institutional perspective seeks to draw attention to the battery of actors who are responsible for grounding capital in particular spaces at particular times. It argues that whilst wider structural factors cannot be ignored, it is towards more empirical analysis of particular relationships between the actors who mediate between capital and the built environment that greater attention needs to be given.

By focusing on the ways in which different actors are involved in the urban development process and the relations between them, these studies have shifted the emphasis away from a circuits of capital approach towards one that addresses the neglected area of the negotiated and mediated positions adopted by agents and agencies relative to local, regional, national and global forces. This is aptly summarised in Healey and Barrett's (1990: 90) call for a new research agenda for the 1990s: "the critical task for the analyst seeking to understand the process of production of the built environment is an examination of how such external pressures are reflected in and affected by the way individual agents determine their strategies and conduct their relationships as they deal with specific projects and issues, and as they consider their future stream of activities" (italics in original).

\subsubsection{Property mobilising agents}

In selecting companies for this study, we have taken cognisance of the typologies produced in both of these traditions. Whilst we appreciate the need to position property players in relation to the circuits of capital from which they derive, we have found it impossible to obtain the necessary company-based data for this to be practicable. Our sampling frame was not, therefore, drawn up on the basis of the ultimate origins of the sources of capital involved in property development in urban Scotland. On the other hand, we find persuasive aspects of the institutional perspective, which downplays the significance of locating capital at a deeper level in any case, and which focuses on the array of actors who mobilise capital markets of whatever origins. The merits of this institutional approach have been the enhanced emphasis placed on those agents and agencies involved in property development and the recognition that their interests need reflect not only wider economic arguments.

Consequently, in developing our typology we have tended more towards the institutional perspective and its more disaggregated accounts of the key players. There is, however, one theoretical point within this perspective with which we cannot agree. Whilst we do recognise the need to locate any one actor within the sets of relations operating in the context of any one development, we do not see this forbidding the possibility of intercepting only some tiers of the process. In relation to property politics the institutional perspective would argue that there is a need to contextualise the activities of any one 
player against the background of the political behaviour of other players. In so doing, there is a tendency to overemphasise the singularity of the political activities associated with any one development and to downplay the fact that different actor groups might share a common political agenda. In other words, all property-marketing agents must surely be thought of as having a different political agenda from say property developers or property investors. The point we are making is that there is a dynamic to the political behaviour of property companies which goes beyond the sets of relations associated with individual development projects. Therefore, our sample frame has sought to identify a collection of companies who perform similar roles in the property development process.

Although in the literature the group we refer to has most frequently been termed developers, we reject this terminology and advocate instead the term 'property mobilising agents'. As defined here the role of property mobilising agents is threefold: first, such companies must be actively involved in investing capital in office, industrial or retail property; second, they must be investing with the purpose of enhancing the value of the property through refurbishment, redevelopment or subdivision; and thirdly, they must have the intention to sell or lease property to other companies. By adopting this definition, we are explicitly excluding from the study companies who invest in domestic and housing property, those who invest without an intention to enhance the property value through development, and those who invest as owner occupiers.

In focussing upon this group we do not wish to downplay the significance of the property politics which might be generated by these other actors. Clearly, these additional types of agents can be expected to have different sets of relations with the state and thus adopt different practices of politicking. Nevertheless, as defined, property mobilising agents would seem to be a term with theoretical integrity capturing a cohort of capital in the development process which is likely to be unique. We argue this for two reasons. First, and if there is any merit in the local dependence argument, this group should be more politicised insofar as its attachment to place ought to be more strongly developed by virtue of its engagement in three activities; investment, development and selling/leasing. Second, and given these multiple roles, property mobilising agents ought to be engaging with state policy and initiatives on a wider front than those actors excluded.

Working with this definition the companies which form part of our sample frame, therefore, cut across some of the categories which might be recognised by the institutional analysts. Fig. 5 tries to summarise the broad categories of actors who are of greatest relevance. Aside from the state-which is clearly not the subject of this paper-four other mobilising actors are recognised: developers, land owners, property owners, and property financiers. Obviously not all companies in these categories in Scotland perform each of the three functions necessary for inclusion here. Only a fraction of each will form the basis of the survey sample. Further, whilst not forming the main thrust of this paper, Fig. 5 also illustrates the way in which, amongst these mobilising agents, some will have a closer relationship, firstly, to specific parts of the development process (ie. a development company whilst categorised here as a mobilising agent may still be required to be identified as a developer in other settings) and, secondly, to some circuits of capital than others (e.g. property owners may be in the primary circuit, whilst property financiers will feel more at home in the finance circuit). 


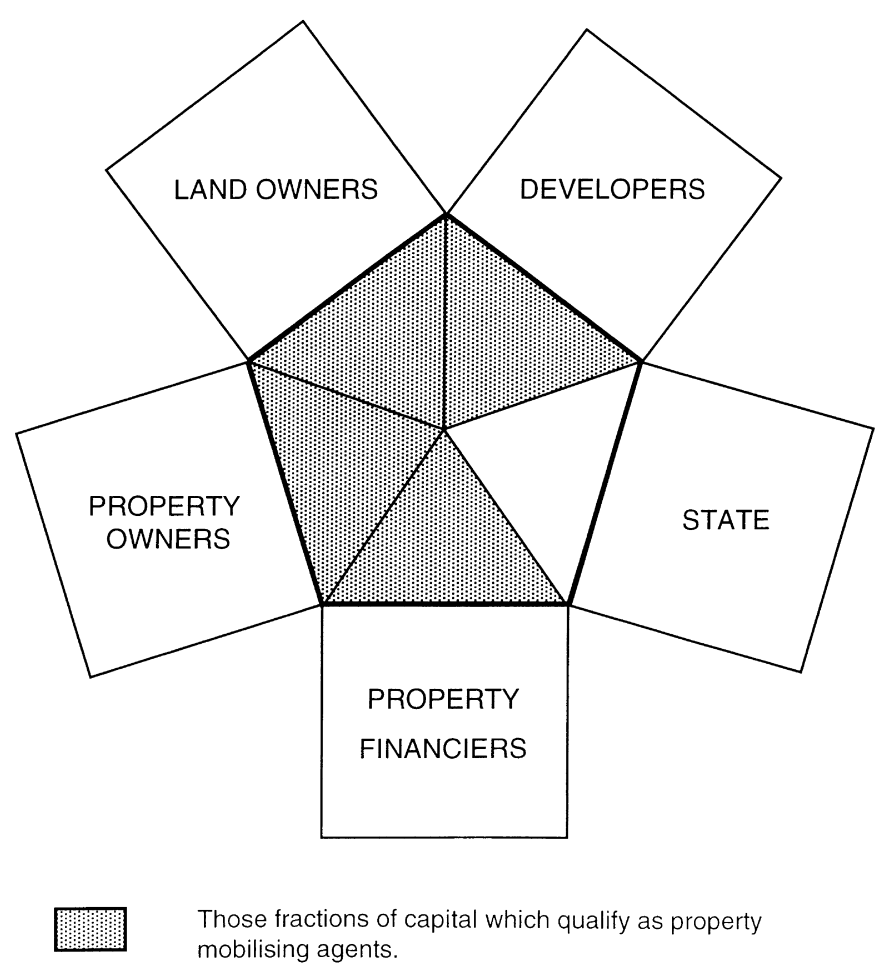

Fig. 5. Defining property mobilising agents.

\subsection{Identifying property mobilising agents in Scotland}

Having sought to contextualise our category of property mobilising agents within general typologies available in the literature, we turn attention here to the mechanics of identifying the range of property mobilising agents who operate specifically in Scotland. This task has involved three stages. First, a database was generated using secondary data sources which contained diagnostic information about companies which might qualify under the above definition. Second, this database was refined through a telephone survey to produce the sample frame. Third, and finally, a questionnaire survey was sent to each of these companies in order to explore their involvement in property politics. We consider the questionnaire survey results in Chapter 4.

\subsubsection{Constructing the database}

Identifying those mobilising agents involved in property development in urban Scotland is not easy. Certainly analysis of available datasets suggests that the kinds of categories the academic literature in general identify do not resonate with those employed within the industry. With complex sets of relations between capital sources and mobilising agents, and with the involvement of companies ranging from global organisations through to local, single site actors, it is unsurprising that no single database of agents exists in the 
Table 5

Criteria met by business directories

\begin{tabular}{llll}
\hline Business directory & $\begin{array}{l}\text { Comprehensive } \\
\text { coverage }\end{array}$ & Up-to-date & Delineation \\
\hline Dun and Bradstreet-Key British Enterprises 1997 (Top & $\sqrt{ }$ & $\sqrt{ }$ & $\sqrt{ }$ \\
50 000 Companies) & & & $\sqrt{ }$ \\
Dun and Bradstreet Scottish Business Register 1997 & $\sqrt{ }$ & $\sqrt{ }$ & $\times$ \\
Scotland's Top 2000 Companies-Financial Survey 1997 & $\sqrt{ }$ & $\sqrt{ }$ & $\sqrt{ }$ \\
Property Trade Directory 1997-Directory of Estate Agents & $\times$ & $\sqrt{ }$ & $\sqrt{ }$ \\
in the UK & & & $\sqrt{ }$ \\
Regional Sales Leads 1997 & $\times$ & $\sqrt{ }$ & $\sqrt{ }$ \\
Smaller UK Companies Handbook-1997/Financial Times & $\times$ & $\sqrt{ }$ & $\times$ \\
The Company Guide 1997 & $\times$ & $\sqrt{ }$ & $\times$ \\
Scottish Property Network & $\times$ & $\sqrt{ }$ & $\sqrt{ }$ \\
Scottish Chambers of Commerce Directory 1997 & $\times$ & $\times$ & $\sqrt{ }$ \\
Who owns Whom 1997/1998 (Dun \& Bradstreet) & $\times$ & $\times$ & $\times$ \\
Directory of Glasgow Companies 1995 & $\times$ & $\times$ & \\
Kompass-Volumes I-III & $\times$ & & $\times$ \\
Directory of property developers, investors and financiers- & $\times$ & $\times$ & $\times$ \\
1988/89 & & $\times$ & $\times$ \\
F.A.M.E.-Financial Accounts Made Easy & $\times$ & $\times$ & \\
Jordan's Britain's Top 3000 Property Developers 1991 & $\times$ & $\times$ & \\
Jordan's-Britain's Top 10 000 privately owned businesses. & $\times$ & & \\
\hline & & & \\
\hline
\end{tabular}

UK. This conclusion was confirmed in initial enquiries with the Royal Institution of Chartered Surveys, Investment Property Databank (IPD), and Ryden International property consultants.

Consequently, our research began with a review of the more general business directories available in the United Kingdom. Given the research aims of the project, each directory was assessed on three key criteria:

- the extent to which comprehensive coverage of the property sector was achieved;

- how up-to-date the available information was;

- the degree to which a clear delineation could be made between companies in the property sector and other companies listed.

As shown in Table 5, the only directories that satisfied all three criteria were the Scottish Business Register and Key British Enterprises, both published by Dun and Bradstreet. These directories, therefore, were chosen to create the basic database from which the research could progress.

In addition to meeting the basic criteria, another key benefit derived from the use of these two Dun and Bradstreet directories was that their shared authorship ensured that information was provided on a comparable, systematic basis. Furthermore, the similar notation used in each directory made cross-referencing between the directories relatively easy.

These two directories undoubtedly give the most comprehensive list of property and property-related industries available. The Key British Enterprises directory lists the top 
Table 6

Standard Industrial Classification codes used in constructing the database

\begin{tabular}{ll}
\hline US SIC code & Category title \\
\hline 1531 & Operative builders \\
1541 & Industrial building contractors \\
1542 & Non-residential building contractors \\
3312 & Blast furnaces, Steelworks \\
4469 & Miscellaneous water transportation services \\
5141 & General grocery wholesalers \\
6012 & Authorised banks and deposit takers \\
6111 & Miscellaneous financial institutions \\
6311 & Life assurance \\
6351 & Surety insurance \\
6371 & Pension, health and welfare \\
6411 & Insurance agents, brokers and services \\
6512 & Non-residential building operations \\
6519 & Miscellaneous real property lessors \\
6531 & Real estate agents and managers \\
6552 & Subdividers and developers (not cemeteries) \\
6711 & Holding companies \\
6724 & Unit investment trusts \\
6799 & Miscellaneous investor \\
7361 & Employment agencies \\
7392 & Managing consultants and public relations \\
7699 & Miscellaneous repair services \\
8331 & Job training and vocational services \\
8399 & Miscellaneous social services \\
\hline
\end{tabular}

50000 companies in the UK and, therefore, the largest companies with headquarters in Scotland. The Scottish Business Directory compiles details of headquarters and branches located in Scotland. As it includes companies with more than 5 employees or annual sales turnover exceeding $£ 250000$, a range of small to very large companies were included.

Given their general coverage, these directories failed to offer a straightforward mechanism through which property mobilising agents could be directly sifted out. Therefore, it was necessary to start by constructing a database consisting of all companies which might conform to the definition of mobilising agents cited above. This task required a selection of US Standard Industrial Classification (SIC) codes to be employed as a common reference point. These codes were identified in two ways. First, all codes listed in the directories under the heading of 'property' were included, and where individual entries of companies also referred to other SIC codes these were added to the list. Second, and augmenting the directories, the Scottish Property Network (SPN) based at the University of Paisley (see Chapter 2) was requested to provide information on additional SIC codes which might be of relevance. Table 6 lists the SIC codes of the categories used in the compilation of the initial database, with those categories in bold being represented in the final sample frame (see 3.2.2. below). This initial database was dominated by four groupings: builders with 1500 codes; financial institutions (codes 6000-6300); property groups (6500 codes) and investors (6700 codes). The other SIC groups had fewer than five entries in each. 
Initially, the Key British Enterprises directory was used to derive a list of property mobilising agents. The chosen SIC codes were identified and cross-referenced by geographical regions, with the information on companies with headquarters in Scotland recorded. The same SIC code method was used with the Scottish Business Register where every additional HQ entry that came under a relevant SIC code was entered into the database. Where branch entries appeared, the available information was also recorded, as was the location of the company's HQ. Through this process of construction, a total of 831 companies were identified in this database.

\subsubsection{Constructing the sample frame}

This database was employed in an initial attempt to ensure comprehensive coverage of all possible relevant property and property-related companies operating in Scotland. However, partly because of its derivation from general directories constructed obviously for reasons beyond this research and also because of the wide scope of the SIC categories employed, it was anticipated that of the 831 companies in this database, some-if not many - would lie outside of the category of mobilising agent discussed earlier. Indeed, it was difficult from the data contained in the directories to ascertain even the degree to which the companies had an involvement in property development, and an involvement in Scotland. Given our desire to sieve out only those companies meeting our requirements, each of the 831 firms were contacted to refine the database. An initial telephone survey was conducted in which the following filter question, defining mobilising agents, was employed:

"does [your company] invest in commercial, industrial or retail property for the purpose of refurbishing, redeveloping or subdividing this property to sell, or to lease out to other companies?"

If respondents answered "yes" to this question, they were sent a copy of the survey questionnaire and included in the revised database. If respondents answered "no", the nature of their company's business was noted and they were placed in the "non-property mobilising agent" category. This filtering process resulted in the original database of 831 companies derived from the Dun and Bradstreet directories being refined as shown in Table 7 below.

The 189 companies who had been identified as property mobilising agents were sent a survey questionnaire. This questionnaire was divided into four sections. In the first section, information was sought on the characteristics of the company in order to allow greater insight into its structure. This was followed by a section, which in general terms attempted to ascertain the different tiers of government which the firm had been active in lobbying and the different channels through which they had voiced opinions. In the final two sections, attention turned to political lobbying of local government and LECs respectively, asking the respondents to detail specific ways in which they had engaged with both of these agents of local governance. Through the use of a variety of contacts with the companies, including follow-up telephone calls and further letters of explanation and copies of the survey questionnaire, a response rate of $57.1 \%$ was obtained. A total of 108 companies, therefore, provided information and it is upon these responses which Chapter 4 is constructed. 
Table 7

Refining the database

Number of companies

Property moblising agents

A Answered: questionnaire returned by target company 108

B Declined to respond $\quad 39$

C Not answered $\quad 42$

Total

189

D Not property mobilising agents

$\begin{array}{ll}\text { Active in residential market only } & 72\end{array}$

Builders/solicitors/etc with no property/investment development functions 117

Fund/trust managers involved in sharemarket only 46

Equipment leasing $\quad 5$

Bank only $\quad 9$

Financiers of property development $\quad 4$

Deer hunting estates 3

$\begin{array}{ll}\text { Completely different sector } & 101\end{array}$

Company listed under another name in the list 11

$\begin{array}{lr}\text { Company collapsed } & 12\end{array}$

Umbrella or subsidiary company with property arm/subsidiary elsewhere on 95

list

Umbrella or subsidiary company of another firm (non-target) 4

$\begin{array}{ll}\text { Merged with another firm on list } & 6\end{array}$

$\begin{array}{ll}\text { Taken over by another firm } & 4\end{array}$

Property interests totally managed by another firm on list 1

$\begin{array}{ll}\text { Trust fund managed by another firm on list } & 9\end{array}$

Do have holdings in Scotland but constitute approx. 1\% of total 1

$\begin{array}{ll}\text { Questionnaire returned by no-targeted company } & 37\end{array}$

Total

537

E Unable to trace company

No listing in phonebook

Same listing in phonebook, but out of business $\quad 32$

$\begin{array}{lr}\text { Sent back through post and no company listing } & 2\end{array}$

$\begin{array}{ll}\text { Engaged/no answer multiple times } & 13\end{array}$

Number not recognised and new number not recognised 4

Number not recognised, new number obtained, no answer 4

Total

105

Grand total

831

\subsection{Characterising the property mobilising agents}

Prior to engaging with the data on property politics derived from these survey responses, we wish, first, to profile a number of the principal characteristics of the survey population which can be gleaned from the secondary data sources employed to construct the database and, second, to summarise what we perceive to be the principal methodological contributions which this research has made. In considering the characteristics of the survey 
Table 8

Key characteristics of property companies listed in Dun and Bradstreet

Company name

Company structure: headquarters, branch, holdings not in Scotland

Headquarters location: in Scotland, United Kingdom

Directory source:-Key British Enterprises, Scottish Business Register, SPN

Accounting parentage-listed company is parent or is subsidiary

Company location: town, county, postcode

Contact details: telephone number, fax number, Director's name

Year of establishment

Standard Industrial Classification (SIC)

Level of sales $(\mathfrak{f})$ from the latest year recorded. Sales, turnover, total assets

Profit or loss from the latest year recorded

Number of employees

population of 189 companies, it is important to note that no claims are being made here that these firms are representative of the entire population of mobilising agents responsible for shaping urban Scotland. Given the above process, the most that can be claimed is that the 189 firms represent some of the largest mobilising agents active in Scotland.

Previous research on property developers has typologised such agents in terms of production output, operational characteristics, financial and market power, and size and number of employees (CALUS, 1979; Leung, 1986; Fothergill et al., 1987). Whilst the two main secondary data sets utilised-Dun and Bradstreet Key British Enterprises 1997 and Dun and Bradstreet Scottish Business Register 1997_-proffered a list of a variety of firm characteristics (Table 8), in practice only a minimum number of such indicators are available for this analysis. In many instances we found that different pieces of data were missing making aggregate analysis too piecemeal to be meaningful. Particularly, measures such company turnover, profit/loss, and total assets, which would clearly have been useful, are listed in such an inconsistent way as to render these criteria inaccessible for this analysis. A review of the indicators which are sufficiently represented points to five as most deserving of inclusion (listed in bold in Table 8).

Following our survey, it has become obvious that, in some instances, data collected directly from companies conflicts with that provided in the Dun and Bradstreet directories. This might become apparent to the reader in the next chapter, where we produce a more detailed typology of the 108 respondents using data derived from our primary survey. Of course, given that Dun and Bradstreet was published in 1997 and our survey was not conducted until spring 1998, observed differences might simply be due to changing company circumstances through time. On occasions, however, it would seem that data differ by orders of magnitude, suggesting that differences might reflect some more deep-seated problem in that the methodology utilised by Dun and Bradstreet might have extracted different answers to those obtained through direct contact with companies. We do not wish to speculate on the causes of these differences, nor whether our data are more accurate than that provided by Dun and Bradstreet. To draw such conclusions would require a separate analysis of the methodologies used in both instances. This is clearly beyond the scope of this paper. We thus operate on the assumption that both datasets have 
Table 9

Company status (Source: authors' survey. Note: percentages may not add up to 100 because of rounding.)

\begin{tabular}{lll}
\hline & Survey population & Sample \\
\hline Parent & $90(48 \%)$ & $55(51 \%)$ \\
Subsidiary & $29(15 \%)$ & $16(15 \%)$ \\
No data & $70(37 \%)$ & $38(35 \%)$ \\
Total & 189 & 108 \\
\hline
\end{tabular}

integrity within their own terms of reference, and that provided the origins of the data are clearly specified, it is legitimate to undertake typological analysis using both datasets.

The following tables (Tables 9-13) make use of the five indicators (shown in bold in Table 8 ) to portray the profile of the 189 property mobilising agents making up the survey population. From these tables it would appear that:

- the bulk of the firms are parents in their own right, with a minority of the survey population listed as subsidiaries (Table 9);

- the majority of companies (over 80\%) are Scottish based, and that whilst the big four Local Enterprise Company areas, based around the conurbations of Glasgow, Edinburgh, Dundee and Aberdeen, are the dominant Scottish locations (housing 62\% of all firms), mobilising agents are to be found further down the hierarchy and beyond Scotland's largest cities (Table 10);

Table 10

Company location, by Local Enterprise Company area (Source: authors' survey. Note: percentages may not add up to 100 because of rounding.)

\begin{tabular}{lcc}
\hline Location & Survey Population & Sample \\
\hline Glasgow Development Agency & $50(26 \%)$ & $25(23 \%)$ \\
Lothian and Edinburgh & $31(16 \%)$ & $18(17 \%)$ \\
Enterprise & $19(10 \%)$ & $10(9 \%)$ \\
Scottish Enterprise Tayside & $19(10 \%)$ & $13(12 \%)$ \\
Grampian Enterprise & $6(3 \%)$ & $4(4 \%)$ \\
Ayrshire Enterprise & $6(3 \%)$ & $3(3 \%)$ \\
Fife Enterprise & $6(3 \%)$ & $2(2 \%)$ \\
Lanarkshire Development & $5(3 \%)$ & $4(4 \%)$ \\
Agency & $5(3 \%)$ & $2(2 \%)$ \\
Forth Valley Enterprise & $2(1 \%)$ & $2(2 \%)$ \\
Renfrewshire Enterprise & $1(1 \%)$ & $1(1 \%)$ \\
Scottish Borders Enterprise & & $1(1 \%)$ \\
Dumfries and Galloway & $1(1 \%)$ & $1(1 \%)$ \\
Enterprise & $4(2 \%)$ & $15(14 \%)$ \\
Dunbartonshire Enterprise & $22(12 \%)$ & $7(6 \%)$ \\
Highlands and Islands Enterprise & $12(6 \%)$ & 108 \\
London & 189 & \\
England (other) & & \\
Total & & \\
\hline
\end{tabular}


Table 11

Company size as measured by number of employees (Source: authors' survey. Note: percentages may not add up to 100 because of rounding.)

\begin{tabular}{lcc}
\hline \multirow{2}{*}{ Number of employees } & \multicolumn{2}{l}{ Number of firms } \\
\cline { 2 - 3 } & Survey population & Sample \\
\hline $1-5$ & $24(13 \%)$ & $18(17 \%)$ \\
$6-10$ & $41(22 \%)$ & $24(22 \%)$ \\
$11-15$ & $15(8 \%)$ & $7(6 \%)$ \\
$16-30$ & $17(9 \%)$ & $9(8 \%)$ \\
$31-100$ & $33(17 \%)$ & $18(17 \%)$ \\
$101-200$ & $11(6 \%)$ & $6(6 \%)$ \\
$201-400$ & $9(5 \%)$ & $4(4 \%)$ \\
$401-1000$ & $5(3 \%)$ & $5(5 \%)$ \\
$1001-5000$ & $6(3 \%)$ & $4(4 \%)$ \\
$5001-50000$ & $8(4 \%)$ & $5(5 \%)$ \\
$>50000$ & $1(1 \%)$ & $1(1 \%)$ \\
No data & $19(10 \%)$ & $7(6 \%)$ \\
Total & 189 & 108 \\
\end{tabular}

- whilst a significant number of firms are very small (35\% of the survey population have 10 or fewer employees), the dataset is composed of companies of a variety of different sizes. Indeed, almost $40 \%$ of the survey population employs over 30 people, with 9 companies employing greater that 5001 employees and one company actually employing over 50000 employees (Table 11);

- whilst some companies have been in existence for some time (18\% of the survey population indicating a date of establishment prior to 1950, and indeed one (Aberdeen Harbour Board) indicating twelfth century origins), the vast majority of firms in the survey population date from 1950 onwards. Indeed with over $50 \%$ of firms being established since 1970, and 40\% having existence from 1980 onwards, it is clear the backbone of the survey population is of recent origins. This chimes with the concept that the growth of mobilising agents, at least in their current form, has been a recent one (Table 12);

Table 12

Date of establishment of companies (Source: authors' survey. Note: percentages may not add up to 100 because of rounding.)

\begin{tabular}{lll}
\hline Date of establishment & \multicolumn{2}{l}{ Number of firms } \\
\cline { 2 - 3 } & Survey population & Sample population \\
\hline Pre 1950 & $34(18 \%)$ & $21(20 \%)$ \\
$1950-1959$ & $10(5 \%)$ & $7(6 \%)$ \\
$1960-1969$ & $18(10 \%)$ & $12(11 \%)$ \\
$1970-1979$ & $27(14 \%)$ & $16(15 \%)$ \\
$1980-1989$ & $50(26 \%)$ & $28(26 \%)$ \\
$1990-1998$ & $27(14 \%)$ & $13(12 \%)$ \\
No Data & $23(12 \%)$ & $11(10 \%)$ \\
Total & 189 & 108 \\
\hline
\end{tabular}


Table 13

Official SIC Codes of Sample and Survey (Source: Authors' survey. Note: Percentages may not add up to 100 because of rounding.)

\begin{tabular}{lcc}
\hline SIC code (US) & Survey population & Sample \\
\hline 6531 Real estate agents and managers & $36(20 \%)$ & $17(16 \%)$ \\
6552 Subdividers and developers & $22(12 \%)$ & $10(9 \%)$ \\
6519 Miscellaneous real property lessors & $18(10 \%)$ & $12(11 \%)$ \\
1541 Industrial building contractors & $17(9 \%)$ & $10(9 \%)$ \\
6512 Non-residential building operations & $14(7 \%)$ & $6(6 \%)$ \\
6799 Miscellaneous investor & $14(7 \%)$ & $9(8 \%)$ \\
6711 Holding companies & $13(7 \%)$ & $6(6 \%)$ \\
1542 Non-residential building contractors & $10(5 \%)$ & $6(6 \%)$ \\
1531 Operative builders & $9(5 \%)$ & $8(7 \%)$ \\
6311 Life assurance & $6(3 \%)$ & $4(4 \%)$ \\
6724 Unit investment trusts & $5(3 \%)$ & $4(4 \%)$ \\
6111 Miscellaneous financial institutions & $5(3 \%)$ & $2(2 \%)$ \\
Other SIC Codes $<5$ & $20(11 \%)$ & $14(13 \%)$ \\
Total & 189 & 108 \\
\hline
\end{tabular}

- mobilising agents reside within a disparate group of SIC codes, with codes 6531,6552 , 6519, and 1541 dominating (Table 13).

Using the indicators available from the Dun and Bradstreet directories, the above tables also illustrate some typological comparisons of the survey population (189) and sample of respondents (108). From the data which can be gleaned from these secondary data sources it would seem that the survey population tends to have a slightly greater proportion of parent firms to subsidiaries, Scottish companies to English ones, and companies of recent (to a significant extent post-1980s) origin. Fundamentally, however, there would appear to be no evidence to suggest that firms falling under the different sets of classification used above were more or less likely to participate in the questionnaire survey. The lesson to be learned for future studies which seek to investigate the political activities of mobilising agents is that it is worthwhile covering all bases as there appear to be no systematic tendencies for any particular type of mobilising agent to be more or less likely to complete a questionnaire.

\subsection{Summarising the methodological contributions}

To end this chapter, it is worth reflecting on what we believe to be the three key methodological contributions provided by the research design employed here. First, whilst in most studies of the property industry the role of the developer has been viewed as pivotal, precise definition of such players has been lacking. In offering an alternative focus on property mobilising agents, we suggest a more robust category that serves to pin down three specific characteristics of significance in interpreting property politics. In this respect, we provide a less problematic term in identifying property agents who are involved in investment into property, who are active in the enhancement of property 
value through development, and who trade locational advantage through the leasing and selling of property.

Second, in addressing the problem of a lack of a national database of key property players, this study has provided a first attempt at producing a database of property mobilising agents in particular. What is evident is that it is not possible to use existing general business directories to devise a list of such players or indeed to draw on the Standard Industrial Classification system for this purpose. Even when sieving general business directories for relevant companies, it has of course to be acknowledged that they tend to cover only the largest companies in the UK (thus excluding overseas companies) and, on occasions, only Scotland. They, therefore, cannot be used to identify a representative sample for research purposes.

Third, and finally, this chapter has shown that once mobilising agents have been identified there would appear to be no systematic tendency in the likelihood of certain firms responding to academic research surveys. It would appear that our response rate is immune to the variations in those key characteristics which can be gleaned from business directories. It is worthwhile, therefore, for future research to attempt a comprehensive coverage since no efficiency gains can be achieved by targeting specific company types. It is towards an analysis of the companies who did respond to the questionnaire survey that attention now turns. 


\section{CHAPTER 4}

\section{Property politics in Scotland}

In this chapter, we aim to provide a broad overview of the main results produced through our survey of property mobilising agents in urban Scotland. Our focus is confined, therefore, to the 108 companies who completed the questionnaire. It is worthwhile at this stage, restating the four major aims of the survey outlined in the first chapter. These were:

- to assess the degree to which property mobilising agents are politically active in Scotland, gauging the importance of local level activity in relation to political activity at higher levels of government;

- to examine the main channels through which property mobilising agents articulate their concerns to the state;

- to ascertain whether there are any differences in the lobbying behaviour of different types of property mobilising agents;

- to assess whether the recent shifts in the structures and strategies of urban governance have created new sites of political lobbying.

All four of these aims will be examined in this chapter. We begin, however, by using background information on firms collected through the survey to provide a more detailed typological analysis than was possible in the previous chapter. At this stage, the objective is to clarify some of the more important characteristics of companies that might help in the interpretation of differences between mobilising agents in terms of their political behaviour.

\subsection{Characteristics of survey respondents}

Given the limitations of the secondary datasets described in the previous chapter, background information collected on companies as part of the survey provides a useful backdrop to any analysis of their political behaviour. As noted in Chapter 3, data collected on company characteristics in the survey deviates in many instances from that provided in the secondary datasets used. Our method of coping with such differences has been to assume that both secondary and primary data used herein have integrity within their own terms of reference. As our data on political activities derives solely from our questionnaire survey, and given that we requested more comprehensive and detailed information on company characteristics in the questionnaire, we operate only with our primary survey data here.

We now consider three key diagnostic characteristics-company size, geographical location, and nature of activity - to provide an overview of the 108 respondents. Whilst these three characteristics offer only limited coverage, the intention is to furnish readers with sufficient insight into the types of firms which comprised the sample so as to render their reading of the rest of this paper's analysis of property politics in Scotland more comprehensible. Perhaps inevitably, efforts to discern whether there exist any distinctive differences in the characteristics of firms raise more questions than they answer. Thus, for 
Table 14

Turnover and turnover generated through property (Source: Authors' survey of 108 property mobilising agents.)

\begin{tabular}{lll}
\hline Million pounds & \multicolumn{2}{l}{ Number of companies } \\
\cline { 2 - 3 } & Total annual turnover & Annual turnover from property \\
\hline$<1$ & $22(20.4 \%)$ & $31(28.7 \%)$ \\
$1-9.9$ & $40(37.0 \%)$ & $38(35.2 \%)$ \\
$10-99.9$ & $17(15.7 \%)$ & $13(12.0 \%)$ \\
$>100$ & $11(10.2 \%)$ & $6(5.6 \%)$ \\
Missing & $18(16.7 \%)$ & $20(18.5 \%)$ \\
\hline
\end{tabular}

example, we resist the desire to refine further our typological analysis through a series of cross-tabulations. Instead we offer a brief overview of each categorisation without drawing out inter-relationships.

\subsubsection{Company size}

To the extent that company size has an influence on the volume and nature of companies' political activities, it is useful to ascertain whether firms displayed any systematic differences in terms of size. In the survey, company turnover and number of employees were noted as two indicators of size. In regard to company turnover, firms were first asked their total turnover in the last financial year. Of the 90 firms who completed this section, 1 in 4 indicated turnover of less than $£ 1$ million, with a further $44 \%$ having turnover of between $£ 1$ million and $£ 10$ million. The survey also identified 11 'super-rich' companies each generating a total income greater than $£ 100$ million (Table 14).

Assuming that property activities might constitute only part of companies' overall business, and in a desire to clarify the absolute turnover of companies activities in regard to their property activities, companies were also asked to state the proportion of their total turnover which could be attributed to the property sector. Table 14 also portrays the broad divisions here. Two points are worth observing. Firstly, once other areas of company activities have been stripped away, there is a slightly greater tendency for some property mobilising agents to cluster at the lower end of the size scale, with nearly $64 \%$ having less than $£ 10 \mathrm{~m}$ turnover in property and fewer companies having greater than $£ 100 \mathrm{~m}$. However, secondly, perhaps more striking is the fact that for most companies, and especially smaller ones, the majority of turnover is generated in property. What the survey points to, therefore, are generally high levels of property-dependence amongst the companies.

\subsubsection{Geographical structure}

The second dimension to be considered here is the geographical structure of the company. At one level, this can simply be measured in terms of headquarters location. Table 15 highlights headquarters location by local council areas. It is evident that Glasgow and Edinburgh dominate the Scottish scene, housing over $40 \%$ of headquarters, whilst Dundee and Aberdeen together form a second tier. The table illustrates the high level of 
Table 15

Location of company headquarters (Source: author's survey of 108 property mobilising agents.)

Local authority area Number and proportion of companies

with headquarters in area

\begin{tabular}{lrr}
\hline Glasgow & 27 & $25.0 \%$ \\
Edinburgh & 16 & $14.8 \%$ \\
Aberdeen & 6 & $5.6 \%$ \\
Dundee & 7 & $6.5 \%$ \\
Other districts with $2-4 \mathrm{HQs}^{\mathrm{a}}$ & 20 & $18.5 \%$ \\
Other districts with $1 \mathrm{HQ}^{\mathrm{b}}$ & 8 & $7.4 \%$ \\
England, Wales and & 24 & $22.2 \%$ \\
international &
\end{tabular}

\footnotetext{
${ }^{a}$ Local authority areas of Aberdeenshire, Ayr, Falkirk, Fife, Kincardine and Deeside, Midlothian, North Lanarkshire, and Scottish Borders.

${ }^{\mathrm{b}}$ Local authority areas of Clackmannanshire, Dumfries and Galloway, East Dunbartonshire, Inverclyde, Highland, Renfrewshire, South Lanarkshire, and West Lothian.
}

Scottish headquarters amongst the property mobilising agents. Seventy eight per cent of headquarters are found here.

Beyond company headquarters location, it is also instructive to examine the geographical distribution of companies' property business and, in particular, to gauge the extent to which companies are more or less dependent on the Scottish market. In the survey, all firms were asked to indicate the proportion of their turnover generated through property business within Scotland, and the proportion of staff involved in property business who were located in Scotland. Since both displayed identical trends, only the proportion of 'property' staff located in Scotland will be cited here. The picture which emerges is of a polarised, geographical structure. A significant majority of companies (67 of the 108) employ their entire property-related staff in Scotland and a further 9 had between 80\% and $99 \%$ here. For the bulk of the sample, therefore, there exists high levels of dependency on the Scottish property market. On the other hand, however, one quarter of companies (28) had fewer than half their property employees in Scotland and were, thus, considerably less dependent on their Scottish operations.

This picture of dependence can be elaborated on by shifting to a more local scale of analysis. Table 16 portrays the dispersion of company operations across Scotland. One quarter of the property mobilising agents are locally dependent; in the sense that their

Table 16

Geographical distribution of company interests within Scotland (Source: authors' survey.)

\begin{tabular}{lll}
\hline $\begin{array}{l}\text { Number of local } \\
\text { council areas with } \\
\text { property interests }\end{array}$ & $\begin{array}{l}\text { Number and proportion of } \\
\text { companies }\end{array}$ \\
\hline 1 & 28 & $25.9 \%$ \\
$2-5$ & 55 & $50.9 \%$ \\
$6-10$ & 19 & $17.6 \%$ \\
$11-15$ & 6 & $5.6 \%$ \\
\hline
\end{tabular}


entire operations are confined to a single local council area. Three quarters of those companies responding to the survey had property operations in more than one local council, with 19 operating in up to 10 councils and a further 6 active in 11-15 council areas. Thus whilst there may indeed be considerable dependency on Scottish operations, for most property agents within Scotland their dependency is not restricted to one council area.

\subsubsection{Nature of activity}

A key criteria which can be employed to distinguish firms is the nature of their involvement in the mobilisation of capital. Firms were asked to provide self-definitions of their involvement in property. Of primary interest here is the way in which all firms tended classify themselves into one of three categories: investors, developers, or investors and developers. Whilst these categories were not included in the questionnaire and therefore are not based upon our own a priori assumptions, to the companies these distinctions appeared to be clear cut and all sought to locate themselves into one of the three groups. Whilst investors were primarily finance companies investing in the built environment as part of an asset portfolio, developers were defined as companies exclusively interested in building property for sale or rent in the short term. Whilst investors more often deployed their own capital, developers activities were shaped by their capacity to mobilise capital (from all over the financial markets) as part of speculative developments. Investors and developers were perceived as companies who engaged in both activities. Of the 108 companies responding to the survey, $23(21 \%)$ were investors only, $47(44 \%)$ defined themselves as both developers and investors, whilst $38(35 \%)$ defined themselves as developers only. Aside from performing these core roles, many companies indicated that they had further interests in property; one company indicating that they performed five additional roles (landlord, lessor, marketing agent, solicitors, and factor). There appeared to be no systematic tendency, however, for firms in any one category to be more or less likely to perform additional functions. Given that these three categories emerged from the companies' self descriptions, and that they, therefore, seem to constitute their core identities, they mark out an important division-one that we will return to Chapter 4.4.

It will be recalled from Fig. 5 that irrespective of the nature of the work they do, firms might also be located more generally within the overall property development process. Four categories of role were specified in Fig. 5: developers, land owners, property owners, and property financiers. From the information provided by the survey, it proved impossible to classify all 108 companies accurately into one of these four roles. We, therefore, have no overall picture of the relative importance of each. As Table 17 illustrates, it is clear nonetheless that all four were represented in the sample at some level.

\subsection{The importance of local political activity}

In this section we address the extent to which contacts exist between property mobilising agents and different tiers of the state. Particularly, our concern is with the relative importance of local level political activity in comparison to political behaviour at larger geographical scales. In the survey, respondents were asked at which levels of government 
Table 17

Examples of the different roles played by property mobilising agents

\begin{tabular}{llll}
\hline $\begin{array}{l}\text { Developers as } \\
\text { mobilising agents }\end{array}$ & $\begin{array}{l}\text { Landowners as } \\
\text { mobilising agents }\end{array}$ & $\begin{array}{l}\text { Property owners as } \\
\text { mobilising agents }\end{array}$ & $\begin{array}{l}\text { Property financiers as } \\
\text { mobilising agents }\end{array}$ \\
\hline $\begin{array}{l}\text { Alba Homes } \\
\text { Bell Properties Ltd }\end{array}$ & $\begin{array}{l}\text { Aberdeen Harbour Board } \\
\text { Birkby plc }\end{array}$ & $\begin{array}{l}\text { Grosvenor Developments } \\
\text { Malcolm Campbell Ltd }\end{array}$ & $\begin{array}{l}\text { Barclays Group Property } \\
\text { Britannia Investment } \\
\text { Management Ltd }\end{array}$ \\
James Keiler Estates & Buccleugh Estates & Scotmid Coop & \begin{tabular}{l} 
CIS Ltd \\
\hline
\end{tabular}
\end{tabular}

they had voiced their viewpoints on any government policy or initiative. The options provided were the local council, LECs, the Scottish Office, national UK government and the EU, with multiple responses to these options being possible.

Table 18 illustrates the different tiers and the number of property companies which engaged with each. Of the 108 respondents, $73.1 \%$ replied that they had contacted at least one tier of government. The pattern across the tiers is intriguing. Perhaps unsurprisingly, given the acknowledged patterns of state-business relations noted in previous studies, the vast majority of those companies which have contacted the state-70 of the 79 respondents - did so at the local council level. At each of the higher tiers of the state, there was a marked decline progressively in the number of companies contacting that level of the state to a point where only 3 contacted the European Union. Furthermore, there was a low level of contact with national government (19 respondents) and even at the Scottish Office level fewer than 1 in 5 companies had responded to initiatives and policies.

What conclusions can be reached from this table as to the level of politicisation of property mobilising agents? At one level these agents must be regarded as being politically active, since nearly three-quarters had made representations to government. What this data does not show, however, is the qualitative aspects of this contact; in particular the strength, depth and direction of this activity. At a second level, it is evident that the local level does dominate political activity and most noticeably that local councils form the key object of company's actions. To the extent that one can take these patterns as testimony of genuine political lobbying, it would seem that it is indeed at the urban level in Scotland that most attention needs to be given by research.

Whilst Table 18 provides a sense of the differential rates of engagement with the state, it was clear that many companies contacted government at more than one tier, with potentially different and complex patterns of engagement existing. Do these patterns therefore

Table 18

Tiers of political activity by property mobilising agents (Source: authors' survey.)

\begin{tabular}{ll}
\hline Tier of government & Number of companies engaging \\
\hline Local council & 70 \\
Local enterprise company & 29 \\
Scottish office & 25 \\
UK government & 19 \\
European union & 3 \\
No contact & 29 \\
\hline
\end{tabular}




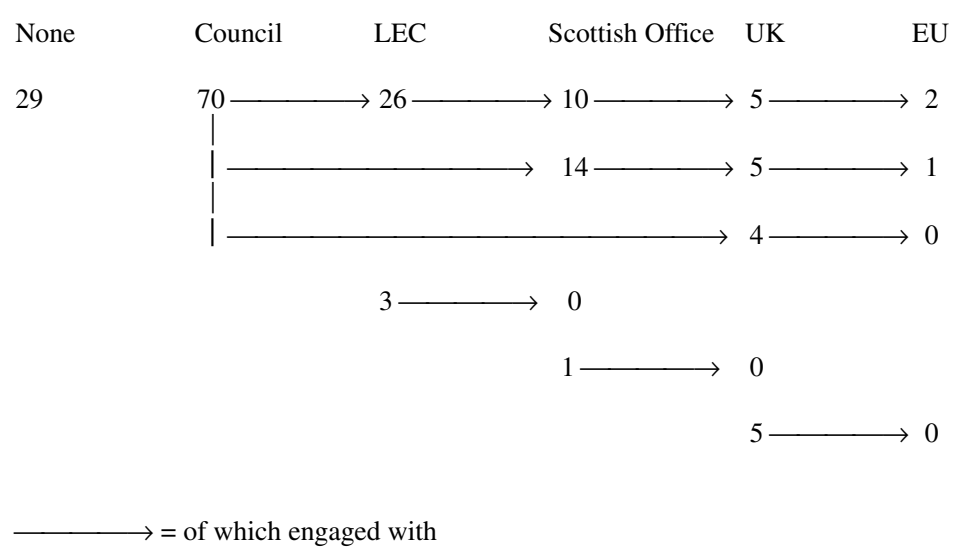

Fig. 6. Tracking contact with tiers of government.

undermine the claim that the urban setting is the most fundamental arena for political activity amongst property mobilising agents? In fact, as Fig. 6 illustrates, a number of clear trends can be identified which further consolidate the pre-eminence of the local scale. First, of the 79 companies who have engaged with the state, only 6 have done so exclusively at tiers beyond the urban level. These are clearly players whose activities bring them into contact with state responsibilities exercised at a more national level. Second, 45 companies' engagement with the state is exclusively at the local level, either through the councils or the LECs alone, or through a combination of these bodies. Furthermore, even among the remaining 28 companies who do make contact with Scottish, British and European levels of government, they too all have contact with the local state, with 16 having engaged with both local councils and LECs. When the profile of individual company activity is tracked across the tiers of the hierarchy (Fig. 6) therefore, it is impossible not to conclude that the institutions of urban governance in Scotland remain at the forefront of property politics.

One remaining question raised by Fig. 6, however, centres on those companies who have not made contact with either the local council or the LEC. Under what circumstances in other words are the agencies of urban governance rendered unimportant by mobilising agents. As part of the survey, the views of those companies not expressing their concerns to councils or LECs - and there were 38 and 79 respondents respectively in this category-were sought to offer insights into their inertia in undertaking political action. Each respondent was requested to indicate which of five options best described their position with regard to the local council/LEC's policies and initiatives. These options ranged from 'few issues of the council/LEC affecting the company' to 'having too little time to engage with local politics'. Multiple responses were allowed and some made use of this possibility. The first column of Table 19 illustrates the range of responses in relation to the local councils with the range of options for the LECs being compared in Table 20.

Tables 19 and 20 illustrate that for most respondents a single reason existed for their non-engagement with local councils and LECs, as shown on the leading diagonals. The 
Table 19

Reasons for not engaging with local councils (Source: authors' survey.)

\begin{tabular}{|c|c|c|c|c|c|c|}
\hline Range of options & A & B & $\mathrm{C}$ & $\mathrm{D}$ & $\mathrm{E}$ & Total \\
\hline $\begin{array}{l}\text { A-there are few council issues affecting the } \\
\text { company }\end{array}$ & 7 & 1 & 1 & 0 & 3 & 13 \\
\hline $\begin{array}{l}\mathrm{B} \text { - the company is provided with insufficient } \\
\text { information on council policies and initiatives }\end{array}$ & & 3 & 2 & 0 & 1 & 8 \\
\hline $\begin{array}{l}\mathrm{C} \text { - the company has no appropriate channels } \\
\text { of communication to voice its opinions }\end{array}$ & & & 2 & 0 & 1 & 6 \\
\hline $\begin{array}{l}\mathrm{D} \text {-there is no point anyway since council } \\
\text { policy is too remote and inaccessible to } \\
\text { influence }\end{array}$ & & & & 2 & 0 & 3 \\
\hline $\begin{array}{l}\text { E-the company is simply too busy to get } \\
\text { formally involved with politics at the local } \\
\text { level }\end{array}$ & & & & & 8 & 14 \\
\hline \multicolumn{7}{|l|}{$\begin{array}{l}\text { Other responses: } \mathrm{A}+\mathrm{B}+\mathrm{D}+\mathrm{E}=1 \\
\text { No response }=6\end{array}$} \\
\hline Total number of companies $=38$ & & & & & & \\
\hline
\end{tabular}

final column of these tables summarises the total number of companies citing each of the optional responses. Taken together, these data point to three major conclusions. In the case of both the local councils and the LECs, firstly, options A and E predominate, indicating that irrelevance and apathy explain the lack of engagement at this tier. Secondly, however, in the case of the LECs, companies complained that it is ignorance of the LECs policies and initiatives (option B) which has led to their non-involvement. Finally, it is clear that it is not a perception on behalf of companies that local politics is impermeable to influence

Table 20

Reasons for not engaging with Local Enterprise Companies (Source: authors' survey.)

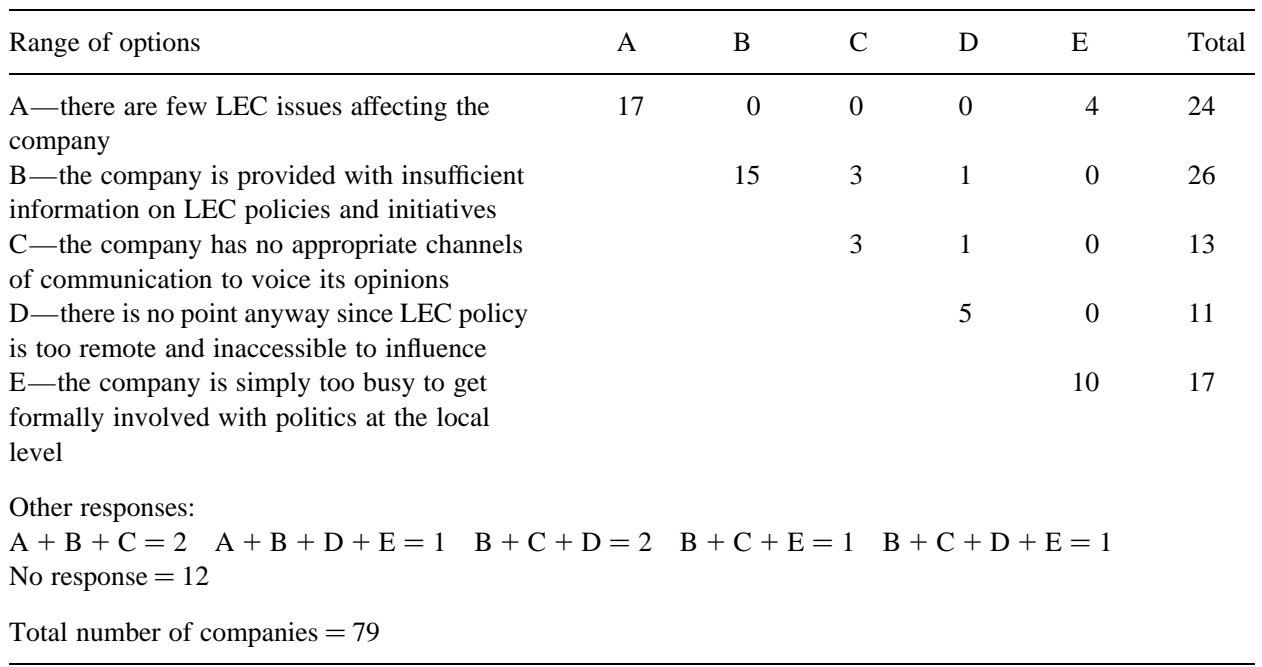


that lead to them opting out of the political process at the local level. What this part of the survey indicates is that amongst property mobilising agents, there is not only a high degree of political action and that much of this is at the local level, but also that the openness of the local political arena to influence is not a perceived barrier.

In summary then, the pattern which emerges in relation to the first research question is of a moderately politicised fraction of capital. Of the 108 companies included in the survey, $79(73.1 \%)$ had 'voiced their viewpoint on any government policy and initiative'. Perhaps most significant was the very high concentration of such political activity at the local level with more than 9 out of 10 companies who politicked addressing viewpoints at this level. Particularly, contact with local government remains predominant with most companies being involved with the local council. On the other hand, approximately $40 \%$ of companies had politicked beyond this level, engaging with more than one tier of government, although the proportion engaging beyond two tiers was limited to fewer than $14 \%$. We conclude from this pattern that property mobilising agents are indeed active in lobbying at the local level in Scotland. In this respect, at least, there are intriguing parallels with the evidence from the US where just such local concentration of political action is evident.

\subsection{Channels used in promoting company viewpoints}

There currently exist three literatures which are in their own ways attempting to yield insights into the mechanisms through which business represents itself to the state. In the North American context, as noted in Chapter 1, the concept of growth machines has been deployed to capture the range of informal alliances which are developing within business communities in North American cities (Logan and Molotch, 1987). In the British context meanwhile, most attention has been given to the ways in which the rise of local quangos are serving to bypass older established channels of business representation. In this case, local coalitions of maverick capital are supposedly displacing older forms of corporate capital (Peck, 1995). Finally, as lobbying has steadily become a commodity some research points to the rise of private sector lobby consultants as new channels for influencing the state (Baggot, 1995). Despite these literatures, little is known of the specific channels employed by the property sector to express property-related views to the state. Consequently as part of our survey, companies were asked to identify the range of channels they employed when expressing their viewpoints to government.

Table 21 illustrates the overall pattern of bodies utilised by those property mobilising agents comprising the sample. Each respondent was offered a list of 12 bodies, identified to represent key players under four sub-groups: government bodies, semi-government bodies, including quangos; private sector lobby groups; and special interest lobby groups in the private sector. Each respondent was also asked to indicate if they had been involved in direct or personal contact with government, had used informal property groups of companies, or other channels outside of this list. Nearly 1 in 4 of the companies had never used channels to lobby government.

Amongst the 82 companies which had deployed at least one channel to access government, four major conclusions can be drawn. First, unlike the situation in the United States the spontaneous formation of loose groupings of property companies do not exist in 
Table 21

Channels of contact with the state (Notes: Other categories provided by respondents. 1. Scottish Homes (1 respondent); 2. Association of British Insurers (2); 3. Industrial Property Federation (2), British Ports Association (1), SBEF (1), Transport Liaison Forum (1), West End Landowners Association (1), NHBC (1), local architect (1), London-based consultancy (1). Source: authors' survey.)

\begin{tabular}{|c|c|c|c|}
\hline Group & Bodies & Number of companies & $\%$ of sample \\
\hline \multirow[t]{5}{*}{ Government bodies } & & 62 & 57.4 \\
\hline & Local council/councillor & 57 & 52.8 \\
\hline & Scottish Office & 23 & 37.1 \\
\hline & MP/Westminster & 24 & 22.2 \\
\hline & MEP/European Parliament & 2 & 3.2 \\
\hline \multirow[t]{4}{*}{ Semi-Government bodies } & & 37 & 34.3 \\
\hline & Scottish Enterprise & 19 & 17.6 \\
\hline & Local Enterprise Company & 32 & 29.7 \\
\hline & Other groups $* 1$ & 1 & 0.9 \\
\hline \multirow[t]{5}{*}{ Private sector lobby groups } & & 37 & 34.3 \\
\hline & RICS & 22 & 20.4 \\
\hline & $\mathrm{CBI}$ & 7 & 6.5 \\
\hline & Chambers of commerce & 18 & 16.7 \\
\hline & Others $* 2$ & 3 & 2.8 \\
\hline \multirow[t]{5}{*}{ Specialist private sector groups } & & 32 & 29.6 \\
\hline & British Property Federation & 20 & 18.5 \\
\hline & Building Societies Association & 0 & 0 \\
\hline & Building Federation & 8 & 7.4 \\
\hline & Others $* 3$ & 8 & 7.4 \\
\hline $\begin{array}{l}\text { Personal/direct contact with } \\
\text { government }\end{array}$ & & 34 & 31.5 \\
\hline $\begin{array}{l}\text { Informal grouping of property } \\
\text { companies }\end{array}$ & & 10 & 9.3 \\
\hline $\begin{array}{l}\text { Never used channels to contact } \\
\text { government }\end{array}$ & & 26 & 24.1 \\
\hline
\end{tabular}

Scotland, with less than $10 \%$ claiming that to be part of such informal groupings. Certainly, a reasonable proportion of companies (31.5\%) have individually taken it upon themselves to make contact with government, but this as close as our data comes to mimicking the North American experience. Second, whilst Peck (1995) argues that there is a sidelining of traditional corporatist interest groups, in relation to the property sector in Scotland in fact there remains evidence of these groups continuing to play an important role in the representation of property interests. For example, the Royal Institution of Chartered Surveyors, the British Property Federation, and the Chambers of Commerce have all been deployed by about 1 in 5 companies. Third, and in contrast to the claim that lobbying is now emerging as a core producer service provided by management consultants, it is intriguing to note that only two companies indicated that they had hired such firms in accessing government. This suggests a low level of penetration of such organisations into the Scottish property arena.

For us, the most important conclusion, however, is the fact that the state is itself not only an object of lobbying but is also a resource which companies attempt to employ in the promotion of their viewpoint. In other words, local councillors, MPs, MEPs, different 
Table 22

Diversity of channels for contact with state (Source: authors' survey.)

\begin{tabular}{ll}
\hline Number of contact groups & Number of respondents \\
\hline 0 & 26 \\
1 & 14 \\
2 & 16 \\
3 & 20 \\
4 & 8 \\
5 & 9 \\
6 & 8 \\
7 & 3 \\
8 & 2 \\
9 & 1 \\
10 & 0 \\
11 & 1 \\
\hline
\end{tabular}

departments and indeed different tiers of government become enlisted in this process as advocates of businesses' agendas. In so doing, property companies continue to place most emphasis on traditional state bodies, such as the local council. Whilst the local quangocracy, therefore, has been designed specifically to channel the voices of business to the rest of government, it would appear that this role plays second fiddle to the traditional arms of the state. If there is a learning curve to the use of Scottish Enterprise and LECs specifically as instruments for the promotion of business agendas, it seems that property mobilising agents remain near the bottom of the curve.

The pattern of different combinations of channels employed by companies provide a further insight. Amongst those companies who did employ channels, the majority deemed one route insufficient in ensuring that their viewpoint was promoted. Indeed, 68 companies employed at least 2 of the 12 channels noted in Table 21, with several using as many as 9 or 11 different channels (Table 22). This would suggest once more that property mobilising agents display a reasonable degree of politicisation. Moreover, of the 80 companies who did engage with at least one of the four groups of channels shown in Table 21 -that is, did not use personal/direct or informal groups to express views - the majority voiced their viewpoints through more than one group, with 26 using channels crossing two groups, and a further 22 crossing three. Indeed 6 respondents indicated that their company had raised issues using all four groups-ie. Government bodies, semi-government bodies, private sector interest groups, and specialist lobby bodies.

In summary, what these two tables establish is that, whilst the literature tends to force analysis down the line of privileging one channel above others, property mobilising agents in urban Scotland remain active in using a diverse range of different groups of channels and an array of more specific mechanisms therein. To focus, therefore, on only one type of conduit to the state would be to miss one key dimension of the landscape of property politics. However, to the extent that any one channel does seem to be most important, these tables also suggest that the literature is in danger of being blind to the role of the state itself in articulating business agendas. Perhaps against expectation, it is those traditional state 


\begin{tabular}{|c|c|c|c|c|}
\hline \multirow{2}{*}{$\begin{array}{c}\text { Tiers } \\
\text { of state }\end{array}$} & \multicolumn{4}{|c|}{ Conduits to the state } \\
\hline & 0 & 1 or 2 & 3 or 4 & $5+$ \\
\hline 0 & 23 & 5 & 1 & 0 \\
\hline 1 & 2 & 17 & 12 & \\
\hline 2 or 3 & 1 & 6 & & 15 \\
\hline 4 or 5 & 0 & 2 & & 4 \\
\hline
\end{tabular}

Fig. 7. Levels of political action.

institutions (particularly local councils) which emerge not only as the object of political action but also as the vehicle.

\subsection{Variations in levels of political activity}

Taken together the above two sections offer an insight into the levels of property politicking in Scotland. The third research questions posed here inquires as to whether there are important variations between property mobilising agents in terms of their propensity to engage with the state. Are there any differences, for instance, discernible along the lines of the company characteristics outlined at the start of this chapter? To address this question, we have brought together the number of tiers at which companies are active and the number of different channels which they employ to provide an overall measure of their level of involvement in property politics. Fig. 7 illustrates this pattern by plotting these two indicators. This figure equates high levels of political action with the dispersion of such action across the political landscape of government and lobby organisations. It is important to note that it does, therefore, point to the intensity of action, which might be concentrated at one scale of government or through one channel; a point which we return to in the following discussions and which can be illuminated better through consideration of the issues on which politicking takes place. What emerges here is a five-fold division of political activity which can be represented as one ranging from non-activists through those with low levels of activity to the most politically active members of the property community.

It would be possible to cross-tabulate companies in each of the five categories defined in Fig. 7 with those characteristics outlined at the start of the chapter, but here we choose to focus on the extremes. Fig. 7 points to one in five of the mobilising agents having no contact with any tier of government or using any channel to express their views. These 23 companies have a significantly greater tendency to be small to medium size companies (that is, those with turnover between $£ 1$ million and $£ 10$ million) and whose property operations form the bulk of their turnover. Further, all but two in this group are parent companies. In comparison with the sample population as a whole, there was also a tendency for investor-developers to be under-represented with a corresponding higher 
proportion of investors. In terms of the geographical distribution of property interests, more than one third had confined their operations to a single council area.

At the other end of the scale, the 19 companies most active in terms of both the number

Table 23

Characteristics of the Most Politically Active Group (Source: authors' survey. Note: 'no response' not presented; proportions may not add up to $100 \%$.)

\begin{tabular}{|c|c|c|}
\hline Key characteristics & Sample population & $\begin{array}{l}\text { Most politically } \\
\text { active mobilising } \\
\text { agents }^{\text {a }}\end{array}$ \\
\hline \multicolumn{3}{|l|}{ Company structure } \\
\hline Parent organisation & 69.4 & 57.9 \\
\hline Subsidiary & 30.6 & 42.1 \\
\hline \multicolumn{3}{|c|}{ Company size: annual company turnover } \\
\hline$<£ 1$ million & 20.4 & 10.5 \\
\hline$£ 1-£ 9.9$ million & 37.0 & 36.8 \\
\hline$£ 10-£ 99.9$ million & 25.9 & 26.3 \\
\hline$£ 100+$ million & 10.2 & 15.8 \\
\hline \multicolumn{3}{|c|}{ Annual company turnover in property } \\
\hline$<£ 1$ million & 28.7 & 10.5 \\
\hline$£ 1 — £ 9.9$ million & 35.2 & 42.1 \\
\hline$£ 10$ —99.9 million & 12.0 & 26.3 \\
\hline$£ 100+$ million & 5.6 & 10.5 \\
\hline \multicolumn{3}{|c|}{ Geographical spread of operations: number of councils } \\
\hline 1 & 25.9 & 10.5 \\
\hline $2-5$ & 50.9 & 68.4 \\
\hline $6-10$ & 17.6 & 10.5 \\
\hline $11-15$ & 5.6 & 10.5 \\
\hline \multicolumn{3}{|l|}{ Nature of activity ${ }^{\mathrm{b}}$} \\
\hline Investor & 21.3 & 15.8 \\
\hline Investor-developer & 43.5 & 47.4 \\
\hline Developer & 35.2 & 36.8 \\
\hline Number of companies & 108 & 19 \\
\hline
\end{tabular}

${ }^{a}$ See text for definition.

b See Chapter 4.1.3 for definitions of nature activity.

of tiers of government and the channels they use to express their viewpoints have a different profile. As Table 23 below portrays, compared with the sample population as a whole, this group consists of firms more likely to be: subsidiaries, have larger total turnover and property turnover, and have operations dispersed across a range of local council areas. Nearly $90 \%$ of this group operate in two or more council areas, and indeed many more cover more than 10 council areas. These larger, less locally dependent companies also tend to fall into the investor-developer category, with an under-representation of investors. 
In interpreting Fig. 7 some caution is necessary. Whilst we have suggested that there is a discernible tendency for those mobilising agents most politically active to have different characteristics in terms of company size, structure, operations and nature of activity from the rest of the sample, it is of course open to debate whether these criteria represent the best means of distinguishing companies in this context. Equally, measuring levels of political activity in terms of tiers and channels could be challenged as the most appropriate method.

But to the extent that there are useful conclusions to be drawn from the data, it would appear that:

- subsidiaries to a greater extent than parent companies are most politically active;

- the largest companies in the sample were the most politically active;

- the least active players tend to operate in only one council area, whilst those most active are more geographically spread and indeed often very spatially diverse in their operations;

- investor-developers tend to be amongst the most politically active, whereas investors tend to be amongst the least active.

Perhaps the most intriguing aspect of these conclusions is the fact that subsidiary companies tended to more active than parents. This is surprising given that parents represent the decision-making core of companies and, therefore, any political action might be anticipated to come through them. One reading of this position would be to suggest that where parents are involved they are strategic in their engagement with the state, employing only a few channels and often limited to only one tier. Alternatively, it could be argued that subsidiaries are the foot soldiers of parent companies and, therefore, perform the politicking roles on behalf of their organisation. In contrast, it is unsurprising that larger companies, investor-developers, and those companies who are more geographically dispersed in their operation are the most politically active. Each of these groups could be anticipated to have reasons to engage across a range of state-property interfaces by virtue of their very roles and functions.

\subsection{Post-Fordist forms of urban governance and the shaping of property politics}

Chapter 2 was dedicated to an analysis of the extent to which the governance of urban Scotland can be said to have undergone a transition. Borrowing from regulationalist inspired analysis, that chapter examined the contention that there has been a demise of the traditional role of the local state in the Keynesian welfare model and a rise of new, post-Fordist structures and strategies. Using seven of the key state-property interfaces identified in Chapter 1 (Table 1) it was argued that whilst elements of the post-Fordist model can certainly be detected in urban Scotland, there is less support for the claim of a wholesale transition. In this section, in an effort to address the fourth research question, we wish to use our survey to examine the extent to which the partial transition to post-Fordism reported in Chapter 2 has served to reshape the policy areas around which property politics concentrates. To this end, as part of the survey, respondents were asked to provide key details about their relationships with local councils and LECs. In each case, respondents were asked to specify their practices and experiences of engagement with these two 
groups. Specifically, they were asked to identify any policy or initiative by the council/ LEC which they felt had affected the performance of their company; and to provide details of the specific councils/LECs and policies/initiatives to which and on which they had made representations.

Before outlining company responses to these two questions, it is worthwhile pausing to reflect upon what the results already outlined (Sections 4.2-4.4) can offer in this respect. One key aspect of the transition to post-Fordism is the notion that the democratic local state is becoming bypassed by private-sector led local quango bodies, who now serve as both the object and vehicle for business interests in the city. As many commentators have noted (e.g. Keating, 1991; Imrie et al., 1995; Peck and Tickell, 1995) the emergence of centrally appointed and directed agencies have marked out one element of the new forms of governance in Britain. What is clear from the survey evidence presented above, however, is that at least in regard to property mobilising agents, there appears to be a lower level of engagement with such bodies than with the more traditional loci of power, the local councils. Not only do nearly twice as many companies contact councils as LECs, but almost all of those who express views to the LECs also contacted councils. Further, councils function as conduits of business agendas to a far greater degree than LECs. Not only, therefore, are local councils more important as objects of politicking but so too they emerge as more significant channels to other branches of the state. There is little evidence of a diminution of the role of the local council in property politics. Whilst it is not possible to postulate a definitive reading at this point, we would advocate the view that the rise of a new institutional landscape in urban Scotland has not as yet served to dislodge the traditional shape of property politics and the pre-eminence of the local council. In other words, at least at this level, there is no evidence to suggest that the rise of post-Fordist structures of governance has fundamentally reshaped the canvas on which property politics is played out.

Of course, this analysis is insufficient to assess properly the full extent to which such reshaping has occurred. In the survey, firms we asked, therefore, to identify the specific policies and initiatives undertaken by councils and LECs which they considered impinged on their company's performance. Using the 12-fold typology of state/property interfaces developed in Chapter 1, we attempt to classify below the responses to these questions (Table 24). This categorisation, in conjunction with qualitative insights provided by companies regarding the nature of their concerns, helps us to go further in assessing the extent to which patterns of property politics have been reshaped by the shift to post-Fordist urban governance.

\subsubsection{Relations to local councils}

Of the 108 respondents, 61 identified issues and initiatives from the councils which in their opinion impinged on their company's performance in the property sector. The second column of Table 24 shows the range and frequency of issues which were raised by respondents about policies emanating from the local council. For the majority of companies concerns lay within the realm of local planning decisions, with 40 of the 68 issues raised being in this category. In contrast far fewer respondents indicated concern about other categories such as subsidies and regional partnerships, state investment in 
Table 24

Number of respondents expressing concern over local state policies/initiatives (Notes: multiple responses possible by the 61 respondents on council policies and 33 on LECs. Italicised state/property interfaces refer to those discussed in Chapter 2. Source: authors' survey.)

\begin{tabular}{lcc}
\hline Type of relation & Local council & Local enterprise company \\
\hline Structures of governance & & \\
$\quad$ Constitutional and legislative arrangements & 0 & 13 \\
Direct intervention in market & 10 & 3 \\
$\quad$ Subsidies and regional partnerships & 1 & 0 \\
$\quad$ Land and property ownership by the state & 0 & 7 \\
$\quad$ Occupier and tenant & 7 & 2 \\
Indirect market intervention & 0 & 0 \\
$\quad$ State investment in infrastructure & & 0 \\
$\quad$ Inward investment strategies & 5 & 0 \\
Regulating property market operations & 0 & 1 \\
$\quad$ Fiscal policies & 0 & 1 \\
$\quad$ Protection of private property & & \\
$\quad$ Regulation of legal system of the property market & 40 & 6 \\
$\quad$ Legislation on design and land-use planning & & \\
Ideological stance & 0 & 2 \\
$\quad$ Place marketing and external postures & & \\
$\quad$ Political culture and internal attitudes &
\end{tabular}

infrastructure, and fiscal policies. And, indeed, none expressed concerns on half of the interfaces noted.

In regard to planning issues, most of the queries revolved around planning applications, or specific property developments and reflected either disappointment with the outcomes of planning decisions or concerns about specific policies, such as greenbelts and listed building consent. The majority of planning issues, therefore, reflected a concern on behalf of the companies regarding the restrictions placed upon development by planning regulations. Perhaps surprisingly, given the limited powers of local councils, there were also comments on the costs to business of the failure to collect council taxes, the impacts of rates relief policy and (in one case) the level of interest rates. This suggests that whilst removed from the real sources of power to shape fiscal policy, the local state is still the recipient of complaints in areas in which it has minor discretion. Further, some companies mentioned the ideological position of councils; reflected in their general attitudes to property. One company based in Aberdeenshire commented on the "lack of initiative and apathy on the part of Council employees" which had affected their performance, whilst another typified their concerns as "all adverse and extremely numerous". Other sets of comments were in effect appeals for action by councils to address infrastructural issues, and these ranged from parking ( 4 mentions) through shopping and retail developments to land regeneration requirements.

Other companies were concerned about the tilting of market conditions through subsidies and local partnerships between the council and property agents. As one company, based in Alloa noted, "the partnerships of [named] council and [named] 
Investments [a large, English based investment company] in Central Business Parks with [named] Construction [a larger, Scottish based constructor] are worrying in that large amounts of public money and effort are put into these projects at the expense of existing investors like ourselves". Whilst all of these are indicative of tensions between agent's roles in the property development process and the activities of the state, as Table 24 indicates only one company offered comments on the tensions which exist between the private sector and the role of council as a property owner. Based in Glasgow, this company commented that "the local council (with LEC) have set up directly in competition thus making local market conditions very difficult for us".

\subsubsection{Relations to local enterprise companies}

Consistent with the patterns of lower levels of contact with the LECs noted above, far fewer respondents had opinions to express about LEC policies and attitudes. Only $33(30.6 \%)$ companies indicated that LEC policies or initiatives had implications for their performance in the property sector. As the final column of Table 24 portrays, the majority of concerns were related to specific infrastructural investments by the LECs, the overall policy and ideological stance of the LECs, or the availability of grants and funding opportunities.

Most of the engagements were of one of two types. At one level, companies politicked LECs less from the perspective of critiquing their intervention in the market and more from the point of obtaining assistance for themselves. For example, LECs were approached about the upgrading of adjacent properties, plans for site development such as the Glasgow waterfront, or about possible joint developments or initiatives, and some companies noted more generally that their involvement with LECs derived from the fact that the LECs were making "investment in physical business infrastructure [which] has helped [the] local economy". A second group of responses related to contacts about financial assistance and grants. Discussions about "local investment funding", "financial support to new business and foreign inward investment in Ayrshire" and "assistance with leg-up and environmental grants" typify the range of comments from this group. Together a total of 20 of the 33 areas of concern were of this type.

On the other hand, in connection with issues relating to the ideological stance of the LECs and their actions in intervening in the market-place, commentaries tended to be decidedly more negative. Of the six companies who noted such issues, only two were perhaps more 'neutral' merely noting that they had made contact with the LEC on these issues. More typically, however, were views which represented hostility to the ways in which LECs had influenced market conditions, such as:

"The change in Scottish Enterprise/LEC strategy towards support for major inward investment, away from start-ups and SMES (locally) has and will impact adversely on our ability to expand our provision of small business premises locally."

"Enterprise companies have offered prospective tenants very cheap uncompetitive rent on industrial units."

"If Scottish Enterprise Tayside (SET) own the land or property themselves we cannot compete with the private sector. New councils and SET want to come together to promote their own interests first." 
One company based in Glasgow with local interests in a part of the city in which the Glasgow Development Agency (GDA) had been active, indicated that the GDA's lack of effective communication impeded relations: "failure of LEC and the Govan Initiative which it supports to consent or communicate with our company on their new involvement in the local commercial property market is a problem". Another respondent summarised their view of the LECs attitude to the private property sector thus; "contacts within LECs as to what they can do for the private sector are very poor-a lot of talking not much action-endless useless statistical reports".

\subsubsection{Interpreting company viewpoints}

From the evidence collected in the survey, we conclude that to the extent that there has been a shift towards post-Fordist urban governance in Scotland, this has not triggered off a corresponding shift in the morphology of property politics. Our results demonstrate the apparent inertia of property mobilising agents in responding to the new opportunities that are being provided to them. It would seem at both the level of the new structures and new practices of governance that a low level of political consciousness prevails. We argue this for two reasons. First, political activity continues to centre on the democratic local state. Furthermore, concerns are primarily registered with the more traditional roles of the state. Despite the rise to prominence of a more entrepreneurial style of governance, the most fundamental concerns of property mobilising agents continue to revolve around planning restrictions and the distorting effects of the local council on the property market. Even when politicking LECs, these agents fail to engage with issues beyond those of market intervention and regulation. Far from embracing the new 'enabling state' property politics continues to focus on what can be characterised as very traditional interfaces with the state.

Second, what is perhaps even more intriguing are those gaps in the current landscape of property politics of urban Scotland. Returning to the debates reviewed at the start of this paper, we find it remarkable that given all that is going around them, property mobilising agents would seem to be singularly disinterested in adjusting to new agendas. For instance, it is incredible that amongst the firms surveyed none had been actively politicking in regard to the constitutional arrangements behind LECs, the privatisation of public property, and the issues surrounding the Private Finance Initiative. Further, very few had taken action in relation to the provision of pump priming by the state, state investment in infrastructure, and inward investment strategies. Finally, in regard to planning issues, it was also clear that companies complaints were largely restricted to specific planning issues and there was no engagement with wider debates about the need to change the architecture and practices of the Scottish planning system.

Despite arguing earlier that the property mobilising agents making up this survey demonstrated a reasonable degree of politicisation, particularly at the local level, a fuller assessment of the nature of local political behaviour would appear to suggest otherwise. This particular cohort of capital may well be active in engaging with the state, but they are failing to appreciate the rapidly changing context within which they are working, have developed no coherent strategies in relation to policy changes, and are failing to step away from a focus on daily, personal concerns to engage with the more philosophical debates which are shaping their future. From the evidence we have 
presented, we would conclude, therefore, that the rise of post-Fordist forms of urban governance has not stamped its imprint on the nature of property politics in Scottish cities. It would seem that whatever the agendas of the state, the property sector occupies a different trajectory.

\subsection{Conclusion}

The empirical analysis of the political activities of the leading property capitals within major Scottish cities presented here is amenable to different levels of interpretation. We leave the wider implications to the next chapter, and concentrate here on summarising what we see as being the most immediate points to arise. On the face of it, in Scotland, property mobilising agents appear to be reasonably politically active. Their activities tend to be directed towards and indeed through local arms of the state, and especially the local council. The issues upon which they take such action, however, have greater affinity with the realms of what can be taken to be an older, more traditional tapestry of local governance. Their concerns, whether expressed to councils or in fact to the LECs, continue to emphasise a sense of immediacy in their political agendas. Further, they seem to be unaware of the significant transformations in the political canvas which is being woven around them. In Chapter 2 it was argued that property politics has to be located within the context of maelstrom of change. Either property mobilising agents have consciously or unconsciously decided that there is nothing in this change of interest, or they are cognitively overwhelmed by it.

In these respects, there is a conflicting picture emerging. On the one hand, the relatively high levels of engagement with, and wide use of many conduits to, the state appear to suggest a level of political maturity more typically identified with the business community in North American cities. On the other hand, framed within a backdrop of neo-liberal state reform, a closer examination of the nature of the state-property interfaces on which firms engage most, points to a less politically conscious fraction of capital. Given the new opportunities for political action, which now exist within this frame, the concerns of property mobilising agents appear oddly anachronistic. Whilst it might be too strong to characterise these agents as 'political dinosaurs', it would certainly be fair to typify their political ambitious as blinkered. In this respect, therefore, property mobilising agents in Scotland might be said to display characteristics which have, indeed, often been attributed to British capital. 


\section{CHAPTER 5}

\section{Moving beyond state-centred perspectives}

The research design adopted in this paper marks out an important new direction in the study of business politics in the city. By choosing to focus on one fraction of capital and the political activities of this fraction across a range of different cities within one political system, we have moved beyond existing work that has tended to be state-centred. The patterns of property politics we have revealed can best be characterised as anachronistic, not only in the issues which are pursued, but also in the institutions which are targeted and the channels employed. Thus, despite the maelstrom of change in state structures and strategies in urban Scotland, property politics still bears the hallmarks of a previous era. Only by designing the research in this way has the apparent disinterest of capital in engaging with the new agendas of the state become apparent.

This said, we wish to conclude by noting that whilst we have adopted a more capitalcentred approach than hitherto, it is still necessary for future research to theorise yet further the extent to which property politics reflect the changing trajectories of capital more than the state's. In exploring property politics as a set of interfaces between capital and state, as shown in Table 1, we could ourselves be criticised for considering only interfaces which reflect functions and activities of the state. A key question which, therefore, remains unasked and unanswered, is what would the property political scene look like if the focus were shifted to the agendas of property agents? It is likely that the interfaces which would be of concern in this instance would either be different from those considered in Table 1, or reflect different readings of the interfaces shown.

By shifting the entry point of analysis of business political activity more towards capital, we are advocating the need for a greater theorisation of the role of different regimes of accumulation rather than modes of regulation in the construction of the agendas around which politicking takes place. In the specific case of property, for instance, we would argue that future research needs to pay greater attention to the location of property mobilising agents within wider accumulation processes. At a theoretical level, it is clear that cycles of development of the built environment can be related to the rhythms of capital accumulation. For example, more use could be made of David Harvey's analyses of the ways in which capital is switched from the primary circuit of production-consumption relations into the built environment, and the more recent research which has suggested a more complex set of relations between capital entering into property development and the wider economy. In particular, with the growing acceptance that there is greater autonomy of the financial circuit from other circuits of capital, there exists new patterns of differentiation in the capitals brought to bear on property development. There is thus a need to examine, more intimately, the impact of such different forms of capital on the process of property-state politics.

If, for instance, the source of capital exists within the primary circuit, most obviously as owner-occupier capital, or is sourced through key elements of the primary circuit (the owner-occupier leveraging capital for property development) then relations with the state might be dominated by local and specific issues associated with individual property developments. On the other hand, if the capital invested in property arises from a crisis 
of accumulation, as Harvey $(1982,1985)$ argues, then the range of intersections with the state may be different, drawing perhaps on a wider range of faces which impact on investment returns. Further, if the source of capital is in the finance circuit then issues relating to fiscal policy, interest rates and other monetary concerns might arguably dominate the political agendas of such property agents. The key point we are making, therefore, is that the morphology of property politics in the city might well reflect the environments of capital rather than those of the state.

In conclusion, we would encourage future research which attempts to theorise the empirical findings contained in this paper to address the following issues:

- what are the origins of capital; that is, from which circuits does capital derive?

- what are the institutional arrangements through which capital is grounded in particular spaces?

- in what ways do the relationships between capital and its intermediaries shape the capacity of these intermediaries to engage with the state?

In other words, in the case presented in this paper, how are the political activities of property mobilising agents in urban Scotland both constrained and enabled by the position of these agents within the different circuits of capital?

In order to move beyond state-centred perspectives, therefore, we are arguing that there may be merit in rehabilitating both the neo-Marxist focus on the city as an expression of wider capital accumulation processes and more recent literature which affords greater attention to the details of the institutional arrangements through which capital is embedded in certain spaces. It could be that both theoretical frameworks might profitably be married to produce a richer account of property politics in the city.

\section{Acknowledgements}

The authors wish to acknowledge the financial assistance received from the Carnegie Trust for the Universities of Scotland, Glasgow City Council and the University of Strathclyde Research and Development Fund in the undertaking of the research on which this paper is based. The authors are grateful to Nicole Cook for her assistance in conducting the survey and in the analysis of the responses from the property mobilising agents.

\section{References}

Axford, N., Pinch, S., 1994. Growth coalitions and local economic development strategy in southern England. Political Geography 13, 344-360.

Baggot, R., 1995. From confrontation to consultation - pressure group relations from Thatcher to Major. Parliamentary Affairs 48, 484-502.

Barras, R. (1979) The development cycle in the city of London. Research Series 36, Centre for Environmental Studies, London.

Boyle, M., Hughes, G., 1994. The politics of urban entrepreneurialism in Glasgow. Geoforum 25, 453-470.

Bryson, J., 1997. Obsolescence and the process of creative reconstruction. Urban Studies 34, 1439-1458.

CALUS (1979) Buildings for industry. University of Reading, College of Estate Management. 
Cochrane, A., Peck, J., Tickell, A., 1996. Manchester plays games: exploring the politics of globalisation. Urban Studies 33, 1319-1336.

Cox, K., 1995. Globalisation, competition and the politics of local economic development. Urban Studies 32, 213-224.

Cox, K., Mair, A., 1988. Locality and community in the politics of local economic development. Annals of the Association of American Geographers 78, 307-325.

EKOS (1998) Strategy for the provision of property for inward investment. Edinburgh, EKOS.

Fothergill, S., Monk, S. and Perry, M. (1987) Property and industrial development. London, Hutchison.

Gallimore, P., Williams, W. and Woodward, D. (1997) Perceptions of risk in the Private Finance Initiative. Journal of Property Finance 8.

Harding, A., 1991. The rise of growth coalitions, UK-style?. Environment and Planning C, Government and Planning 9, 295-317.

Harding, A., 1994. Urban regimes and growth machines: towards a cross-national research agenda. Urban Affairs Quarterly 29, 356-382.

Harvey, D., 1982. The Limits to Capital Oxford, Blackwell, Oxford.

Harvey, D., 1985. The Urbanisation of Capital, Blackwell, Oxford.

Harvey, D., 1989. The Condition of Postmodernity, Blackwell, Oxford.

Hayton, K., 1992. Scottish Enterprise: a challenge to local land us planning?. Town Planning Review 63, 265-278.

Healey, P., Barrett, S., 1990. Structure and agency in land and property development processes: some ideas for research. Urban Studies 27, 80-94.

Imrie, R., Thomas, H., Marshall, T., 1995. Business organisations, local dependence and the politics of urban renewal in Britain. Urban Studies 32, 31-47.

Isaac, D., 1996. Property Development: appraisal and Finance, Macmillan, London.

Jessop, B., 1990. State theory: putting the capitalist state in its place, Polity Press, Cambridge.

Jessop, B., 1995. The regulation approach, governance and post-Fordism: alternative perspectives on economic and political change?. Economy and Society 24, 307-333.

Jonas, A., 1991. Urban growth coalitions and urban development policy: postwar growth and the politics of annexation in metropolitan Columbus. Urban Geography 12, 197-226.

Jonas, A., 1996. In search of order: traditional business reformism and the crisis of neoliberalism in Massachusetts. Transaction of the Institute of British Geographers 21, 617-634.

Jonas, A., Wilson, D., 1999. The growth machine concept: twenty years on, Suny Press, New York.

King, R., 1989. Capital switching and the role of ground rent: 1. Theoretical problems, Environment and Planning A 21, 445-462.

van der Krabben, E., Lambooy, J., 1993. A theoretical framework for the functioning of the Dutch property market. Urban Studies 30, 1381-1397.

Leung, H. K. (1986) Developer behaviour in development control: a Canadian case study. University of Reading, Working Papers in Land Management and Development No. 9.

Leyshon, A. and Thrift, N. (1997) Money/Space: geographies of monetary transformation. London, Routledge.

Lloyd, M.G., Newlands, D., 1988. The 'growth coalition' and urban economic development. Local Economy 3, 31-39.

Logan, J., Molotch, H., 1987. Urban Fortunes: The Political Economy of Place, University of California Press, Berkeley.

Macleod, G., 1998. In what sense a region? Place hybridity, symbolic change, and institutional formation in (post-)modern Scotland. Political Geography 17, 833-863.

Malone, P. (1985) Office development in Dublin: the role of property interests. In Property and the urban environment, A. Maclaran, P. Malone and C. Beamish (eds.). Department of Geography, Trinity College, Dublin, pp. 19-59.

Mitchell, J. (1997) Scotland, the union state and the international environment. In The political economy of regionalism, M. Keating and J. Loughlin (eds.). London, Frank Cass, pp. 406-421.

North, P., Valler, D. and Wood, A. (1999) Towards a constructivist analysis of business agendas for local economic development. Paper presented at Royal Geography Society (with Institute of British Geographers) Annual Conference, Nottingham. 
Offe, C., 1985. The attribution of public status to interest groups. In: Offe, C. (Ed.). Disorganized Capitalism, pp. 221-258.

Goodwin, M., Painter, J., 1996. Local governance, the crises of Fordism and the changing geographies of regulation. Transaction of the Institute of British Geographers 21, 635-648.

Peck, J., 1995. Moving and shaking: business elites, state localism and urban privatism. Progress in Human Geography 19, 16-46.

Peck, J., Tickell, A., 1994. Jungle law breaks out: neoliberalism and global-local disorder. Area 26, 317-326.

Peck, J., Tickell, A., 1995. Business goes local: dissecting the 'business agenda' in Manchester. International Journal of Urban and Regional Research 19, 55-78.

Planning Bulletin. (1998) Recent planning guidance and structure plan progress.

Rogerson, R., Boyle, M., 1998. Glasgow's reluctant mavericks and inward investment: local dependence and its applications. Scottish Geographical Magazine 114, 109-119.

Ryden (1998) Trends in Office Development and locaction in Scotland. Edinburgh, Scottish Office Central Research Unit, 39pp.

Rydin, Y., 1998. Urban and Environmental Planning in the UK, Macmillan, London.

Scottish Enterprise (1998) Annual Report, 1997-1998. Edinburgh, Scottish Enterprise.

Scottish Office (1993) National Planning Policy Guideline: Business and Industry. Edinburgh, Scottish Office.

Scottish Office (1994) National Planning Policy Guideline: the Planning System. Edinburgh, Scottish Office.

Scottish Office (1998) The Government's Expenditure Plans, 1998/1999: Serving Scotland's Needs. Edinburgh, Scottish Development Department.

Scottish Office (1998) National Planning Policy Guideline: Town Centres and Retailing. Edinburgh, Scottish Office.

Scottish Office (1998) Review of Development Planning in Scotland. Edinburgh, Scottish Office Central Research Unit.

Stone, C., 1989. Regime Politics, University Press of Kentucky, Lawrence KA.

Ward, A., 1996. Re-reading urban regime theory: a sympathetic critique. Geoforum 24, 427-438.

Ward, A., 1997. Coalitions in urban regeneration: a regime approach. Environment and Planning A 29, $1493-1506$.

Wood, A., 1993. Organizing for local economic development: local economic development networks and prospecting for industry. Environment and Planning A 25, 1649-1661.

Wood, A., 1996. Analysing the politics of local economics development: making sense of cross-national convergence. Urban Studies 33, 1281-1295.

Wood, A., 1998. Making sense of urban entrepreneurialism. Scottish Geographical Magazine 114, 120-123.

Wood, A., Valler, D., North, P., 1998. Local business representation and the private sector role in local economic policy in Britain. Local Economy 13, 10-27. 